\title{
Safety and Efficacy of Brentuximab Vedotin in the Treatment of Classic Hodgkin Lymphoma
}

This article was published in the following Dove Press journal: OncoTargets and Therapy

\section{Shinichi Makita (D) \\ Dai Maruyama (D) \\ Kensei Tobinai (D)}

Department of Hematology, National Cancer Center Hospital, Tokyo, Japan
Correspondence: Shinichi Makita Department of Hematology, National Cancer Center Hospital, 5-I-I Tsukiji, Chuo-Ku, Tokyo 104-0045, Japan

Tel +8I-3-3542-25II

Fax +8I-3-3542-38I5

Emailsmakita@ncc.go.jp
Abstract: Classical Hodgkin lymphoma (cHL) is a B-cell-derived lymphoid malignancy with the most favorable prognosis among various adult malignancies. However, once it becomes refractory disease to chemotherapy or relapses after high-dose chemotherapy (HDC) with autologous stem cell transplantation (ASCT), it is difficult to manage with conventional cytotoxic chemotherapy. The introduction of brentuximab vedotin (BV) has changed the treatment landscape of $\mathrm{cHL}$ in the past decade. Several studies demonstrated high efficacy of BV monotherapy in heavily treated patients with cHL relapsed or refractory after HDC/ASCT. Recent studies also reported high efficacy of concurrent or sequential combination of BV and chemotherapy in patients with transplant-eligible relapsed/refractory $\mathrm{cHL}$ at the second-line setting. In addition, a randomized phase III trial ECHELON-1 reported a positive result of BV in combination with AVD (doxorubicin, vinblastine, and dacarbazine) in patients with newly diagnosed advanced-stage cHL. In this review, we summarize available data of BV for $\mathrm{cHL}$ and discuss the current and future role of $\mathrm{BV}$ in the management of cHL.

Keywords: brentuximab vedotin, classic Hodgkin lymphoma, CD30, antibody-drug conjugate, MMAE

\section{Introduction}

Classic Hodgkin lymphoma (cHL) is a B-cell-derived lymphoid malignancy with the most favorable prognosis among various adult malignancies. Approximately $80 \%-90 \%$ of patients with newly diagnosed cHL can be cured when treated with the appropriate first-line therapy. ${ }^{1,2}$ However, once cHL becomes a refractory disease to chemotherapy or relapses after high-dose chemotherapy (HDC) with autologous stem cell transplantation (ASCT), it is difficult to manage with conventional cytotoxic chemotherapy. ${ }^{3,4}$ Until recently, advances in the treatment of cHL was primarily based on the modification of conventional cytotoxic chemotherapy and radiotherapy. However, the introduction of brentuximab vedotin (BV), an antibodydrug conjugate targeting CD30, has markedly changed the treatment landscape of $\mathrm{cHL}$ in the past decade. In this review, we summarize available data of $\mathrm{BV}$ for $\mathrm{cHL}$ and discuss the current and future role of BV in the management of cHL.

\section{Targeting CD30 in Lymphoma}

CD30 (initially known as Ki-1) was firstly identified as a specific antigen for Hodgkin and Reed-Sternberg cells in the HL cell line L428. ${ }^{5,6}$ The CD30 molecule is a $120-\mathrm{kD}$ transmembrane glycoprotein receptor that belongs to the tumor necrosis factor 
receptor superfamily. Subsequent studies revealed that its overexpression in cHL is associated with constitutive activation of extracellular signal-regulated kinase 1/2 mitogenactivated protein kinase signaling. ${ }^{7}$ CD30 is also expressed on a small subset of activated B-cells or T-cells ${ }^{8}$ and various lymphoid neoplasms other than cHL. These include anaplastic large cell lymphoma (ALCL) and a subset of peripheral T-cell lymphomas $(58 \%-64 \%$ in peripheral T-cell lymphoma, not otherwise specified; $43 \%-63 \%$ in angioimmunoblastic T-cell lymphoma), ${ }^{9-12}$ adult T-cell leukemialymphoma $(55 \%))^{12,13}$ extranodal NK/T-cell lymphoma $(60 \%-70 \%),{ }^{14,15}$ and diffuse large B-cell lymphoma $\left(14 \%{ }^{-25 \%) .}{ }^{16-19}\right.$ Because CD30 is not expressed on nonhematologic benign tissues or on resting lymphocytes and monocytes, ${ }^{20}$ it is supposed to be an optimal therapeutic target in the treatment of CD30-positive lymphomas.

Nevertheless, naked monoclonal antibodies targeting CD30 demonstrated limited efficacy in patients with CD30-positive lymphomas (Table 1). Ansell et al conducted a phase I/II study of MDX-060, a fully human anti-CD30 immunoglobulin G1kappa monoclonal antibody, in patients with cHL and ALCL. ${ }^{21}$ MDX-060 was well tolerated, and the maximum-tolerated dose (MTD) has not been reached. However, the objective response was observed only in 6 of 72 evaluable patients $(8 \%)$. Similarly, SGN-30 (also known as cAC10), another chimeric mouse-human anti-CD30 monoclonal antibody developed by Seattle Genetics, was tested in a Phase II study in patients with relapsed/refractory cHL and ALCL. ${ }^{22}$ In total, 79 patients (38 with cHL and 41 with

Table I Naked Anti-CD30 Monoclonal Antibody Therapy for $\mathrm{cHL}$ and $\mathrm{ALCL}$

\begin{tabular}{|c|c|c|c|}
\hline \multirow{2}{*}{\multicolumn{2}{|c|}{$\begin{array}{l}\text { Dose and } \\
\text { Schedule }\end{array}$}} & MDX-060 & SGN-30 \\
\hline & & $\begin{array}{l}0.1, \mathrm{I}, 5,10 \text {, } \\
15 \mathrm{mg} / \mathrm{kg}, \text { Weekly } \\
\text { for } 4 \text { Weeks }\end{array}$ & $\begin{array}{l}6 \text { or } 12 \text { mg/kg, } \\
\text { Weekly for } 6 \text { Weeks, } \\
\text { 8-Week Cycle }\end{array}$ \\
\hline $\mathrm{cHL}$ & $\begin{array}{l}\text { Number } \\
\text { of pts } \\
\text { ORR } \\
\% C R\end{array}$ & $\begin{array}{l}63 \\
6 \%(4 \text { of } 63) \\
3 \%(2 \text { of } 63)\end{array}$ & $\begin{array}{l}38 \\
0 \\
0\end{array}$ \\
\hline $\mathrm{ALCL}$ & $\begin{array}{l}\text { Number } \\
\text { of pts } \\
\text { ORR } \\
\% C R\end{array}$ & $\begin{array}{l}7 \\
29 \%(2 \text { of } 7) \\
29 \%(2 \text { of } 7)\end{array}$ & $\begin{array}{l}4 I \\
17 \%(7 \text { of } 4 I) \\
5 \%(2 \text { of } 4 I)\end{array}$ \\
\hline
\end{tabular}

Abbreviations: ALCL, anaplastic large cell lymphoma; $\mathrm{cHL}$, classic Hodgkin lymphoma; CR, complete remission; ORR, objective response rate; pts, patients.
ALCL) were enrolled, but no patients with cHL achieved objective responses. The objective response rate (ORR) in patients with ALCL was only $17 \%$. Another approach for CD30-targeted therapy is antibody-immunotoxin conjugates. Most of the anti-CD30 immunotoxins utilize ribosome-inactivating proteins (RIP) such as saporin, ${ }^{23}$ Pseudomonas exotoxin $\mathrm{A},{ }^{24}$ and ricin $\mathrm{A}$ chain. ${ }^{25}$ These agents demonstrated efficacy in preclinical studies but not in human trials partly because of the high rates of the development of anti-therapeutic antibodies, downregulation of CD30, and non-specific binding of immunotoxin.

\section{Brentuximab Vedotin}

To augment the efficacy of anti-CD30 antibody therapy, a novel antibody-drug conjugate brentuximab vedotin (BV; SGN-35) has been developed. ${ }^{26,27} \mathrm{BV}$ consists of a chimeric anti-CD30 monoclonal antibody (cAC10) and monomethyl auristatin E (MMAE, a microtubuledisrupting agent). It is conjugated by a linker protein that is a highly stable peptide selectively cleaved by lysosomal enzymes (Figure 1A). ${ }^{28} \mathrm{BV}$ binds to CD30 expressed on the surface of lymphoma cells and is internalized via endocytosis. The cytoplasmic lysosomal enzymes decompose the linker protein that conjugates the CD30 antibody and MMAE. The MMAE released to the cytoplasm inhibits the synthesis of microtubules and leads to apoptosis of lymphoma cells (Figure 1B). ${ }^{29}$

Based on the promising results obtained from preclinical studies, a phase I study of BV in patients with relapsed/ refractory CD30 positive lymphomas was conducted. ${ }^{29}$ BV was administered intravenously at doses of $0.1-3.6 \mathrm{mg} / \mathrm{kg}$ in a 21 -day cycle. In total, 45 patients (42 with cHL, 2 with systemic ALCL, and 1 with angioimmunoblastic T-cell lymphoma) received BV. Although BV was well tolerated in each dose level, one patient who received a maximum dose level $(3.6 \mathrm{mg} / \mathrm{kg})$ experienced febrile neutropenia and sepsis, resulting in death 14 days after the first dose of BV. Subsequently, the $1.8-\mathrm{mg} / \mathrm{kg}$ and the $2.7-\mathrm{mg} / \mathrm{kg}$ cohorts were both expanded to include 12 patients each. In the $2.7-\mathrm{mg} / \mathrm{kg}$ cohort, 3 of 12 patients experienced 4 dose-limiting toxicities (DLT): grade 3 acute renal failure, hyperglycemia, prostatitis, and grade 3 febrile neutropenia. Meanwhile, the $1.8-\mathrm{mg} / \mathrm{kg}$ cohort experienced a single DLT in 1 of 12 patients: grade 4 thrombocytopenia. Based on these results, $1.8 \mathrm{mg} / \mathrm{kg}$ was judged as the MTD. The most common adverse events (AE) were fatigue (16 patients, $36 \%$ ), pyrexia (15 patients, 




B

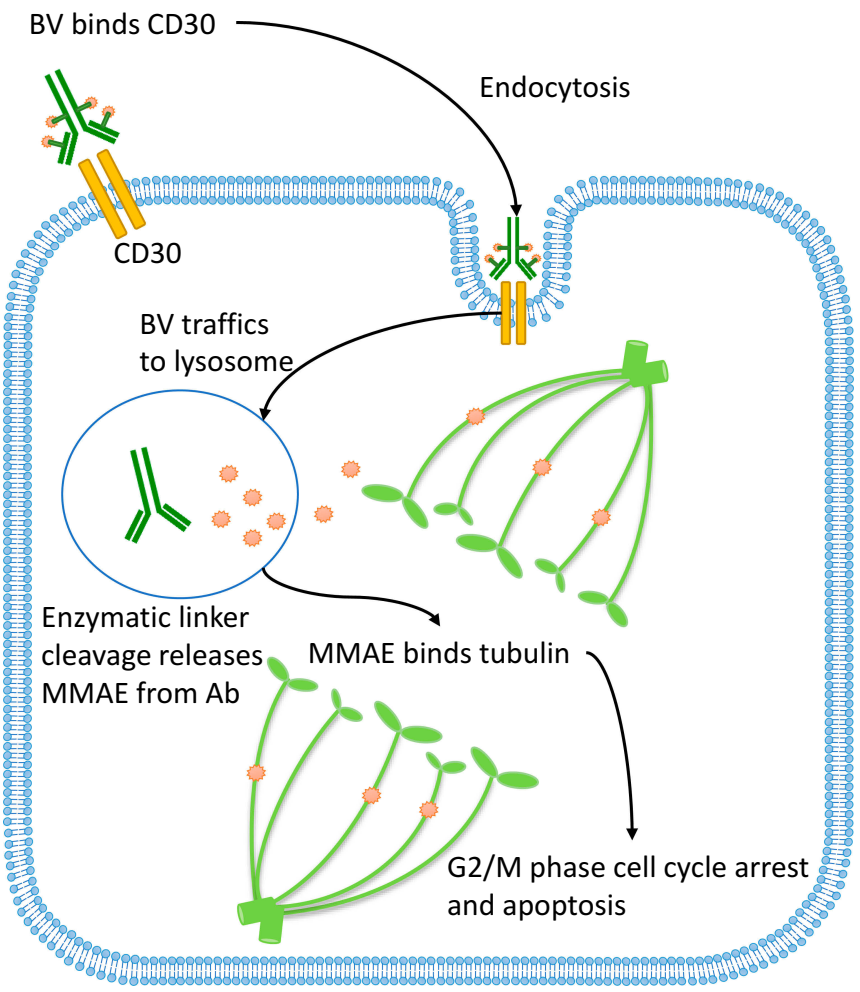

Figure I Brentuximab vedotin (BV). BV is an antibody-drug conjugate consisting of an anti-CD30 monoclonal antibody and the microtubule-disrupting agent monomethyl auristatin E (MMAE) (A). BV binds to CD30 expressed on the surface of lymphoma cells and is internalized via endocytosis. The cytoplasmic lysosomal enzymes decompose the linker protein that conjugates the CD30 antibody and MMAE. The MMAE released to the cytoplasm inhibits the synthesis of microtubules and leads to apoptosis of lymphoma cells (B).

$33 \%$ ), and diarrhea, nausea, neutropenia, and peripheral neuropathy (10 patients, $22 \%$ each), but they were grade 1 or 2 in severity and clinically manageable.

Weekly administration of BV (days 1, 8, and 15; 28day cycle) was also evaluated in another phase I study, and the MTD was judged to be $1.2 \mathrm{mg} / \mathrm{kg} .{ }^{30}$ However, the incidence of peripheral sensory neuropathy was higher than that of the 21-day cycle schedule. ${ }^{29}$ In total, 29 of 44 evaluable patients $(66 \%)$ experienced peripheral sensory neuropathy in this study. Therefore, subsequent studies of single-agent BV utilized a 21-day cycle administration.

\section{Single-Agent BV for Relapsed/ Refractory cHL}

A pivotal phase II study of BV in patients with cHL relapsed or refractory after HDC/ASCT was conducted. ${ }^{31}$ The primary endpoint was overall ORR, and the planned sample size was 100 based on the assumptions of $29 \%$ ORR and that the exact two-sided $95 \%$ confidence interval would exclude an ORR of less than $20 \%$. In total, 102 patients were enrolled and treated with BV at a dose of $1.8 \mathrm{mg} / \mathrm{kg}$ in a 21-day cycle, for up to 16 cycles. The median number of prior lines of therapy was 3.5, and $42 \%$ (43 of 102) of enrolled patients were refractory to the most recent prior therapy. The ORR was $75 \%$ (76 of 102), and the primary endpoint was met. The complete response (CR) rate was $34 \%$ (35 of 102). The median time to objective response was 5.7 weeks. Although BV was well tolerated, one of the most common treatment-related AEs was a peripheral sensory neuropathy. In total, $42 \%$ of patients (43 of 102) experienced sensory neuropathy, and $8 \%$ (8 of 102) experienced grade 3 . Peripheral motor neuropathy was also observed in $11 \%$ (11 of 102). Twenty patients discontinued the treatment because of $\mathrm{AE}$; of them, 9 patients discontinued because of neuropathy.

The estimated 5-year overall survival (OS) and progression-free survival (PFS) rates were $41 \%$ and $22 \%$, respectively, with a median follow-up duration of 35.1 months. ${ }^{32}$ Notably, 38\% (13 of 34) of patients who achieved CR survived without progression for more than 5 years, and 9 of the 13 patients remained in remission without a consolidative allogeneic stem cell transplantation. The data showed that a small subset of patients ( $9 \%$ of the enrolled patients) with relapsed/refractory $\mathrm{cHL}$ may be cured with single-agent $\mathrm{BV}$. 
Based on the promising results of this pivotal phase II study, the US Food and Drug Administration (FDA) granted accelerated approval of BV in 2011 for cHL that relapsed or became refractory after HDC/ASCT or for after failure of two or more prior lines of multiagent chemotherapy in transplant-ineligible patients. It was the first approval of antibody therapy for cHL.

\section{Consolidation Therapy with BV After HDC/ASCT}

Salvage therapy followed by HDC/ASCT has been considered the standard treatment modality for relapsed/refractory cHL. Two randomized trials demonstrated the superiority of HDC/ASCT over conventional chemotherapy without HDC/ ASCT. ${ }^{33,34}$ Further, subsequent studies indicated that about $60 \%$ of relapsed patients and $35 \%$ of refractory patients can be cured with HDC/ASCT, while the remaining experience cHL relapse. ${ }^{35}$ To improve the treatment outcome of patients with relapsed/refractory $\mathrm{cHL}$ who underwent HDC/ASCT, a consolidation with BV after HDC/ASCT was evaluated in a double-blind, randomized phase III trial (AETHERA study). ${ }^{36}$ In this study, patients with at least one of the following unfavorable risk factors were enrolled: 1) primary refractory disease, 2) relapse within 12 months after the first remission, and 3) extranodal involvement at the start of the second-line chemotherapy. The primary endpoint was PFS, and the secondary endpoints were OS and safety. In total, 329 patients were randomly assigned in a 1:1 ratio to the BV arm $(n=165)$ and the placebo arm $(n=164 ; 160$ received allocated intervention). After a median follow-up duration of 30 months, the median PFS by independent review was significantly longer in the BV arm (42.9 months) than that in the placebo-arm (24.1 months), and the study met its primary endpoint (hazard ratio [HR]: 0.57). Interim analysis of OS showed no statistical difference between the two arms. However, the 5-year follow-up data showed that consolidation with BV significantly reduced the need for subsequent therapy compared with placebo $(32 \%, \mathrm{n}=53$ in the $\mathrm{BV}$ arm vs $54 \%, \mathrm{n}=89$ in the placebo arm; $P<.0001)$ and sustained PFS benefit. ${ }^{37}$ Therefore, consolidation with BV after HDC/ASCT is a reasonable treatment option in patients with unfavorable risk factor.

\section{BV in a Second-Line Setting}

Improving the efficacy of the second-line salvage chemotherapy is also an important issue in the management of transplant-eligible relapsed/refractory cHL. Several studies indicated that the pre-transplant disease status, particularly when evaluated with positron emission tomographycomputed tomography (PET-CT) scan, predicts the outcome following HDC/ASCT. ${ }^{38-40}$ The conventional salvage therapies demonstrate substantial efficacy against relapsed/refractory cHL; the ORR is $62 \%-89 \%,{ }^{41-45}$ but their CR rates are only $10 \% 41 \%$ (Table 2 ). Several studies evaluated incorporation of $\mathrm{BV}$ into the chemotherapy at the second-line setting to achieve higher PET-negative $\mathrm{CR}$ rate before HDC/ASCT (Table 3). ${ }^{46-53}$ Moskowitz et al conducted a phase II study to evaluate a PET-adopted sequential combination of $\mathrm{BV}$ and augmented ifosfamide, carboplatin, etoposide (ICE) therapy (Figure 2). ${ }^{46}$ In this study, patients initially received 2 cycles of weekly BV $(1.2 \mathrm{mg} / \mathrm{kg}$, days 1,8 , and 15, 28-day cycle), and the response was evaluated with PET-CT scan. If they achieved complete metabolic response (CMR) (defined as Deauville score 1 or 2 in this study), the patients underwent stem cell mobilization/harvest and subsequent HDC/ASCT. The remaining patients were treated with 2 cycles of augmented ICE therapy and underwent HDC/ASCT if they achieved CMR. Meanwhile, patients who did not achieve CMR after 3 cycles of augmented ICE received other conventional salvage chemotherapy and underwent HDC/HSCT. Of the 45 patients enrolled, 12 (27\%) achieved CMR (Deauville score $\leq 2$ in this study) after 2 cycles of weekly BV and received HDC/ASCT without salvage therapy. Actually, 44\% (20/45) of patients were Deauville score $\leq 3$ after 2 cycles of weekly BV. The remaining patients who were Deauville score $\geq 3$ after 2 cycles of weekly BV received augmented ICE and $69 \%$ (22 of 32) achieved CMR. In total, 76\% (34 of 45) achieved CMR in this PET-adopted sequential strategy. Chen et al also evaluated PET-adopted sequential strategy using conventional dosing and schedule of BV for up to 4 cycles. ${ }^{47}$ Patients received salvage chemotherapy if they cannot achieve CMR

Table 2 Response of Selected Salvage Chemotherapy for Relapsed/Refractory cHL

\begin{tabular}{|c|c|c|c|c|}
\hline Authors & Regimen & No. of Pts & ORR & $\% \mathbf{C R}$ \\
\hline Josting et $\mathrm{al}^{41}$ & DHAP & 102 & $89 \%$ & $21 \%$ \\
\hline Moskowitz et al ${ }^{42}$ & ICE & 65 & $88 \%$ & $26 \%$ \\
\hline Aparicio et $\mathrm{al}^{43}$ & ESHAP & 22 & $73 \%$ & $41 \%$ \\
\hline Bartlett et $\mathrm{al}^{44}$ & GVD & 91 & $70 \%$ & $19 \%$ \\
\hline Kuruvilla et al ${ }^{45}$ & GDP & 34 & $62 \%$ & $10 \%$ \\
\hline
\end{tabular}

Abbreviations: $\mathrm{CR}$, complete remission; $\mathrm{cHL}$, classic Hodgkin lymphoma; DHAP, cisplatin, cytarabine, dexamethasone; ESHAP, etoposide, methyl prednisolone, cytarabine, cisplatin; GDP, gemcitabine, dexamethasone, cisplatin; GVD, gemcitabine, vinorelbine, pegylated liposomal doxorubicin; ICE, ifosfamide, carboplatin, etoposide; ORR, objective response rate. 
Table 3 Selected Clinical Trials of BV Combined with Chemotherapy or Immune Checkpoint Inhibitor for Relapsed/Refractory cHL at the Second-Line Setting

\begin{tabular}{|c|c|c|c|c|c|c|}
\hline Study Group & Regimen & Type of BV Combination & $\mathbf{N}$ & $\%$ CMR & ASCT, n (\%) & PFS/EFS (ITT) \\
\hline $\mathrm{MSKCC}^{46}$ & $\begin{array}{l}\text { Weekly BV } \times 2 \\
+/- \text { AuglCE }\end{array}$ & Response-adapted sequential & 45 & $\begin{array}{l}27 \%^{\mathrm{a}} \text { (BV alone) } \\
69 \%^{\mathrm{a}} \text { (Including-Aug|CE) }\end{array}$ & $\begin{array}{l}34(76 \%) \text { after BV-AuglCE } \\
10(22 \%) \text { after additional Tx }\end{array}$ & $80 \%$ at 2 years \\
\hline City of Hope ${ }^{47}$ & BV $\times 4+/-$ Salvage & Response-adapted sequential & 37 & $\begin{array}{l}35 \% \text { (BV alone) } \\
65 \% \text { (Including salvage) }\end{array}$ & $32(86 \%)$ & $71.9 \%$ at 18 months \\
\hline GELTAMO $^{48}$ & BRESHAP & Concurrent & 66 & $70 \%$ & 60 (91\%) & $71 \%$ at 30 months \\
\hline HOVON $^{49,50}$ & BV-DHAP & Concurrent & 61 & $79 \%$ & $53(87 \%)$ & $76 \%$ at 2 years \\
\hline FHCRR $^{51}$ & BV-ICE & Concurrent & 24 & $87 \%$ & 19 (79\%) & NR \\
\hline LaCasce et al ${ }^{52}$ & BV-bendamustine & Concurrent & 55 & $74 \%$ & $40(72 \%)$ & $62.6 \%$ at 2 years \\
\hline $\operatorname{COG}^{53}$ & BV-gemcitabine & Concurrent & 42 & $67 \%$ & $34(76 \%)$ & NR \\
\hline $\begin{array}{l}\text { Herrera et a }\left.\right|^{58} \\
\text { Moskowitz et } \mathrm{al}^{59}\end{array}$ & BV-Nivolumab & Concurrent & 91 & $67 \%$ & $67(74 \%)$ & $78 \%$ at 2 years \\
\hline
\end{tabular}

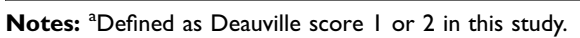

Abbreviations: ASCT, autologous stem cell transplantation; AugICE, augmented ICE; BRESHAP, brentuximab vedotin, etoposide, methyl prednisolone, cytarabine, cisplatin; BV, brentuximab vedotin; CMR, complete metabolic response; COG, Children's Oncology Group; DHAP, dexamethasone, cytarabine, cisplatin; EFS, event-free survival; FHCRC, Fred Hutchinson Cancer Research Center; GELTAMO, Grupo Español de Linfomas/Trasplante Autólogo de Médula Ósea; HOVON, Hemato-Oncologie voor Volwassenen Nederland; ICE, ifosfamide, carboplatin, etoposide; MSKCC, Memorial Sloan-Kettering Cancer Center; Nivo nivolumab; NR, not reported; PFS, progressionfree survival; Tx, therapy.

with BV alone. Overall, 13 of 37 enrolled patients $(37 \%)$ achieved CMR after $\mathrm{BV}$ and underwent HDC/ASCT. Collectively, the results of these studies suggest that about $30 \%{ }^{-} 40 \%$ of patients with relapsed/refractory $\mathrm{cHL}$ can obtain CMR with BV alone. Further, conventional salvage chemotherapy is not required in such population. The response-adapted sequential combination might reduce the risk of subsequent late toxicities associated with intensive cytotoxic chemotherapy. However, caution should be taken because there are no data comparing long-term outcomes after $\mathrm{HDC} / \mathrm{HSCT}$ with regard to $\mathrm{BV}$ monotherapy versus conventional salvage therapy regimens. Further careful evaluation of this strategy is warranted.

Other studies demonstrated higher efficacy (with respect to the $\mathrm{CR}$ rate) of concurrent combination of BV and salvage therapy. A Spanish study group conducted a phase I/II study of etoposide methylprednisolone, cytarabine, and cisplatin (ESHAP) in combination with BV on day 1 (BRESHAP

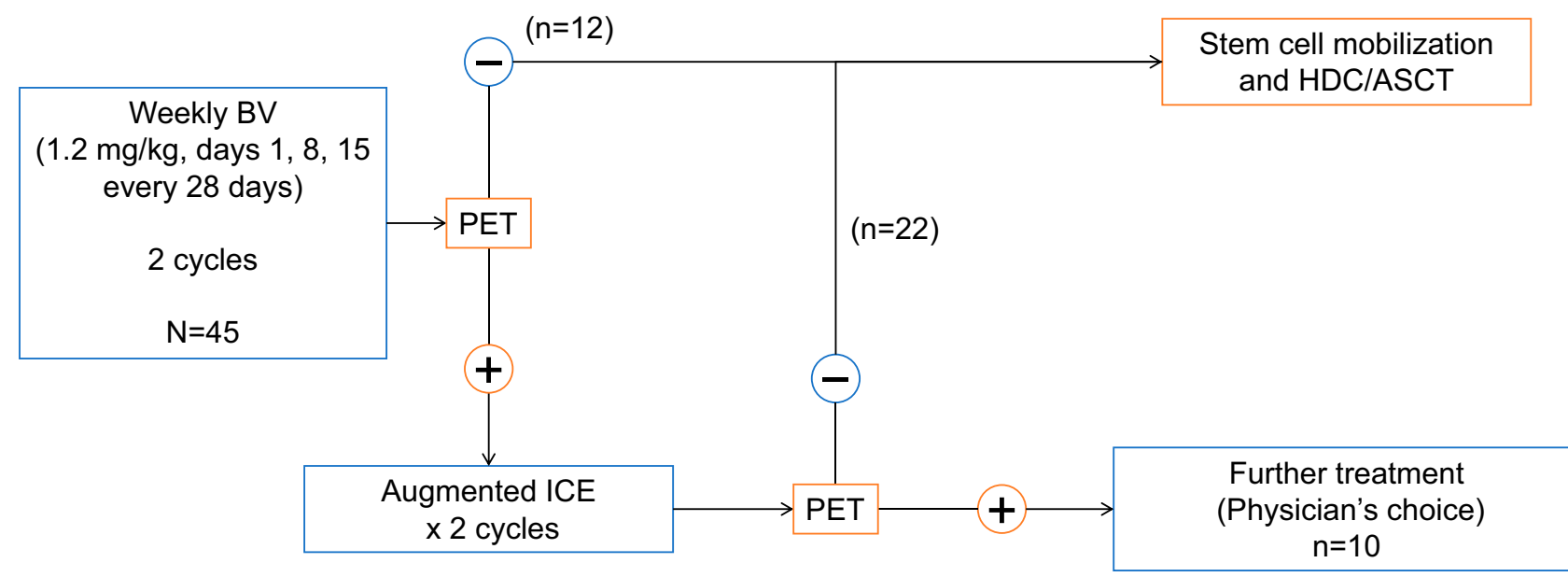

Augmented ICE

Ifosfamide: $5000 \mathrm{mg} / \mathrm{m}^{2}$, days 1,2 , civ (in combination with equal dose of mesna)

Carboplatin: AUC 5, day 3, div

Etoposide: $200 \mathrm{mg} / \mathrm{m}^{2}$, day 1, div (three doses, every 12 hours)

Figure 2 Example of sequential combination of BV and salvage chemotherapy: Weekly BV followed by augmented ICE.

Abbreviations: BV, brentuximab vedotin; HDC/ASCT, high-dose chemotherapy with autologous stem cell transplantation; ICE, ifosfamide, carboplatin, and etoposide; PET, positron emission tomography. 
therapy) (Figure 3). ${ }^{48}$ In the phase I portion, 3 dose levels $(0.9,1.2$, and $1.8 \mathrm{mg} / \mathrm{kg})$ of BV were evaluated, and no DLT was observed. The recommended phase II dose of BV was established as $1.8 \mathrm{mg} / \mathrm{kg}$, which is the same dose of singleagent use. In total, 66 patients were assessed for efficacy, and the ORR and CR rates before HDC/ASCT were 91\% and $70 \%$, respectively. Preliminary studies of BV in combination with other salvage therapies such as dexamethasone, cytarabine, and cisplatin and ICE also reported high CR rates of $79 \%-87 \%{ }^{49-51}$ Although these concurrent combination regimens appear highly effective, hematologic toxicities remain a concern. For example, the incidence of grade 3-4 hematologic toxicities in BRESHAP was approximately 50\% (neutropenia, 50\%; thrombocytopenia, 47\%), ${ }^{48}$ while that in ESHAP was $10 \%-20 \%$ (neutropenia, $10 \%-17 \%$; thrombocytopenia $\left.17 \%{ }^{-} 24 \%\right)^{54,55}$

The combination of bendamustine with BV was also evaluated. A certain efficacy of single-agent bendamustine (120 mg/m², 28-day cycle) for heavily pretreated cHL has already been reported in a single-institute phase II study. The ORR by intent-to-treat analysis was 53\% (19/36), and the CR rate was 33\% (12/36). ${ }^{56} \mathrm{O}$ 'Connor et al conducted a phase I/II study of BV plus bendamustine $\left(90 \mathrm{mg} / \mathrm{m}^{2}, 21\right.$-day cycle) in heavily pretreated $\mathrm{cHL}{ }^{57}$ The median number of prior therapies was 5 (range, $2-12$ ) in the phase I portion $(n=28)$ and 3 (range $1-8)$ in the phase II portion $(n=37)$. The ORR was $71 \%$ (46 of 65), and the CR rate was 32\% (21 of 65). A phase II study conducted by LaCasce et al using this combination as a bridging therapy for HDC/ASCT at the second-line setting showed a higher ORR of $92 \%$ (49 of 53) and CR of 74\% (39 of 53), which is comparable to that of BRESHAP. ${ }^{52}$

BV plus nivolumab might be one of the most promising salvage therapies. ${ }^{58,59}$ Preclinical studies suggested that the MMAE-based antibody-drug conjugates induce endoplasmic reticulum (ER) stress, which leads to immunogenic cell death and antigen presenting cell (APC) activation. As activated APCs promote innate antitumor immune responses, synergistic effects of BV and immune checkpoint inhibitors are expected. $^{60,61} \mathrm{~A}$ phase I/II study of BV in combination with nivolumab in a second-line setting was conducted (NCT02572167); the treatment comprised BV (1.8 mg/kg) and nivolumab $(3.0 \mathrm{mg} / \mathrm{kg})$ in 3-week cycles for up to 12 weeks (4 cycles). After the investigators assessed the response, patients could undergo HDC/ASCT. In total, 91 patients were enrolled in this study; the median age 34 years (range; 18-69), 42\% with primary refractory disease, and $30 \%$ experienced relapse within 1 year of frontline therapy. The ORR for all treated patients was 85\% (77/91) and the $\mathrm{CR}$ rate was $67 \%(61 / 91)$. The most common AEs were nausea $(52 \%)$ and infusion-related reaction (IRR) (43\%). However, IRR was typically only grade 1-2. Immunerelated adverse events (IrAE) that required systemic steroid treatment occurred in $14 \%$ of patients; these including rash (8\%), pneumonitis (4\%), increased AST (1\%), diarrhea $(1 \%)$, and Guillain-Barre syndrome (1\%). With a median follow-up duration of 22.6 months, the estimated 2-year PFS rate in all treated patients was $78 \%$, and for patients who underwent HDC/ASCT after BV + nivolumab, it was 91\%.

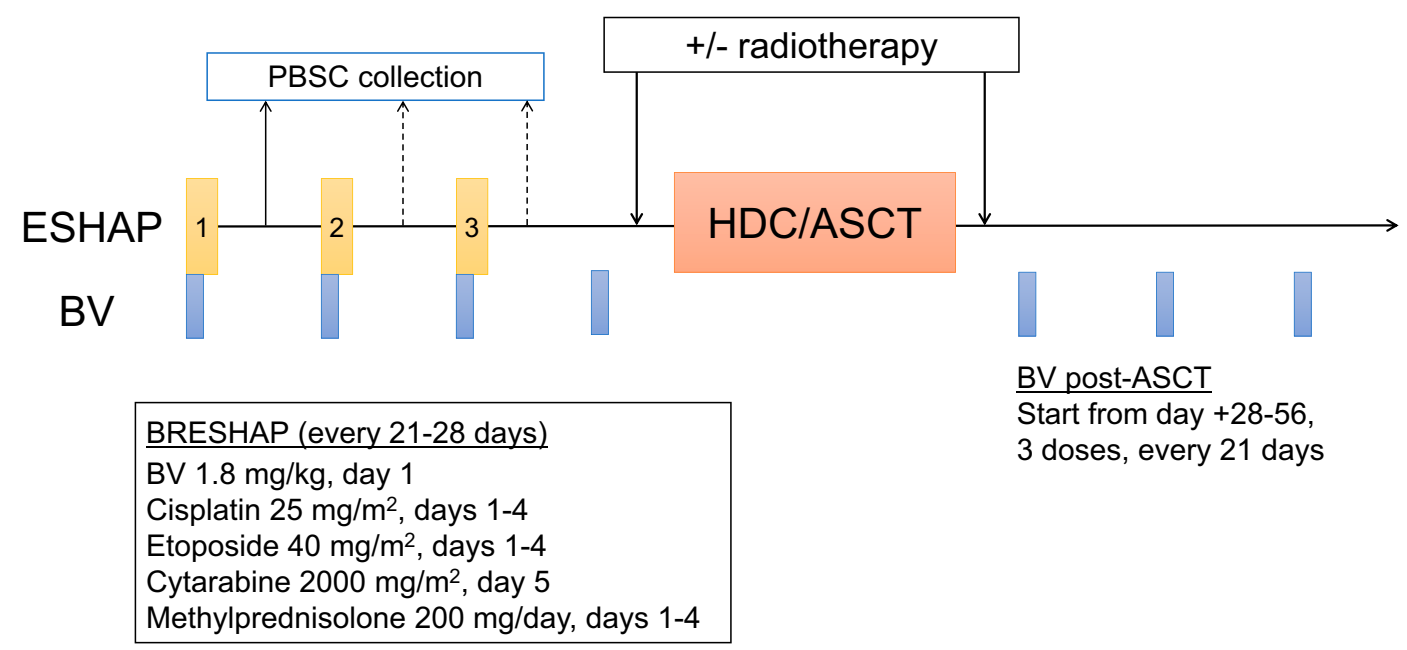

Figure 3 Example of concurrent combination of BV and salvage chemotherapy: BRESHAP.

Abbreviations: BV, brentuximab vedotin; ESHAP, etoposide, methylprednisolone, cytarabine, and cisplatin; HDC/ASCT, high-dose chemotherapy with autologous stem cell transplantation; PBSC, peripheral blood stem cell. 


\section{BV in Combination with Chemotherapy for Untreated Advanced-Stage cHL}

Although cHL is one of the most curable malignancies, patients in the advanced stage have poorer prognosis compared to those with early-stage cHL. ${ }^{2}$ Therefore, several approaches have been evaluated to improve the treatment outcome of these patients. ${ }^{62}$ One approach is a PETadopted dose-intensified strategy based on the interim PET-CT performed after 2 cycles (iPET2) of doxorubicin, bleomycin, vinblastine, and dacarbazine (ABVD). Gallamini et al reported that positive iPET2 is a strong and independent predictor of poor outcomes in patients with advanced-stage cHL. The 2-year PFS of iPET2negative patients was $95.0 \%$, whereas that of iPET2positive patients was $12.8 \% .^{63}$ Based on these results, several study groups conducted an iPET2-guided response-adapted therapy for advanced-stage cHL (Table 4). ${ }^{64-68}$ Overall, approximately $20 \%$ of patients with advanced-stage cHL will be iPET2 positive, and a doseintensified conventional chemotherapy (eg, escalated bleomycin, etoposide, doxorubicin, cyclophosphamide, vincristine, procarbazine, and prednisolone [escalated BEACOPP] therapy) may improve their PFS to up to 60\%-70\%. An iPET2-guided response-adapted strategy appears feasible, and it is one of the reasonable treatment options in this population. However, the negative predictive value of iPET2 does not appear to be superior to that reported by Gallamini et al. ${ }^{63}$ In the early report of iPET2, $95 \%$ of patients with negative-iPET2 achieve progressionfree with ABVD, ${ }^{63}$ whereas approximately $20 \%$ of iPET2negative patients experience relapse in subsequent prospective studies. ${ }^{64-68}$ In addition, the dose-intensified treatment for iPET2-positive patients is not feasible for elderly patients, often requires inpatient treatment, may increase the risk of second primary malignancy, ${ }^{65}$ and has a high risk for gonadotoxicity. ${ }^{69}$

Another approach is a BV-containing chemotherapy. The effectiveness and tolerability of BV for cHL in the relapsed/refractory setting encouraged it to incorporate in the frontline setting. Younes et al conducted a phase I study to evaluate the safety and preliminary efficacy of BV in combination with ABVD therapy for advanced-stage cHL. $^{70}$ Initially, BV was combined with standard ABVD on days 1 and 15 of a 28-day cycle, and 3 dose levels (0.6, 0.9 , and $1.2 \mathrm{mg} / \mathrm{kg}$ ) were evaluated. Although no DLT was observed during the DLT assessment period and the MTD was not reached, 44\% (11 of 25 patients) experienced pulmonary toxicity, which frequently occurred during cycles 3-4. Meanwhile, patients treated with BV + AVD (bleomycin was omitted) $(n=26)$ experienced no pulmonary toxicities. The results suggested that concomitant administration of bleomycin and BV should be avoided. The CR rate in patients with BV + ABVD was 95\% (21 of 22) and that of $\mathrm{BV}+\mathrm{AVD}$ was $96 \%$ (24 of 25). According to the long-term follow-up data, the 5-year failure-free survival in the BV+ ABVD group and the BV + AVD groups were $79 \%$ and $92 \%$, respectively. $^{71}$

Based on this promising efficacy, an international, open-label, randomized phase III study comparing BV + AVD with standard ABVD in patients with advanced-stage cHL (ECHELON-1) was conducted. ${ }^{72}$ The primary endpoint was "modified" PFS, defined as (1) a progressive disease, (2) a non-CR to front-line therapy (Deauville 3-5 at the end-of-treatment PET scan by independent review committee) followed by the delivery of subsequent treatment (including radiotherapy), and (3) any-cause death. In

Table 4 ABVD-Based Response-Adapted Therapy for Advanced-Stage cHL

\begin{tabular}{|c|c|c|c|c|c|c|c|c|}
\hline Study & $\mathbf{N}$ & $\begin{array}{l}\text { Study } \\
\text { Design }\end{array}$ & $\begin{array}{l}\text { Tx Before } \\
\text { iPET2 }\end{array}$ & $\begin{array}{l}\text { Tx for iPET2 } \\
\text { Negative }\end{array}$ & Tx for iPET2 Positive & $\begin{array}{l}\text { \%iPET2 } \\
\text { Positive }\end{array}$ & $\begin{array}{l}\text { PFS of iPET2 } \\
\text { Positive }\end{array}$ & $\begin{array}{l}\text { PFS of iPET2 } \\
\text { Negative }\end{array}$ \\
\hline S08I6 (SWOG) ${ }^{64,65}$ & 336 & Phase II & $A B V D \times 2$ & $A B V D \times 4$ & eBEACOPP $\times 6$ & $18 \%$ & $66 \%$ at 5 years & $76 \%$ at 5 years \\
\hline HD0607 (GITIL) ${ }^{66}$ & 782 & Phase II & $A B V D \times 2$ & $A B \vee D \times 4$ & $\begin{array}{l}\text { eBEACOPP } \times 4(+R) \\
\rightarrow \text { bBEACOPP } 44(+R)\end{array}$ & $19 \%$ & $60 \%$ at 3 years & $87 \%$ at 3 years \\
\hline RATHL (CR-UK) ${ }^{67}$ & 1214 & Phase III & $A B V D \times 2$ & $\begin{array}{l}\text { ABVD } \times 4 \text { vs } \\
A V D \times 4\end{array}$ & $\begin{array}{l}\text { BEACOPPI } 4 \times 6 \text { or } \\
\text { eBEACOPP } \times 4\end{array}$ & $16 \%$ & $67.5 \%$ at 3 years & $\begin{array}{l}85.7 \% \text { at } 3 \text { years } \\
84.4 \% \text { at } 3 \text { years }\end{array}$ \\
\hline HD080I (FIL) ${ }^{68}$ & 520 & Phase II/III & $A B V D \times 2$ & $A B V D \times 4+/-I F R T^{a}$ & IGEV×4 $\rightarrow$ HDC/ASCT & $20 \%$ & $76 \%$ at 2 years & $81 \%$ at 2 years \\
\hline
\end{tabular}



Abbreviations: ABVD, doxorubicin, bleomycin, vinblastine, dacarbazine; bBEACOPP, baseline BEACOPP; BEACOPP, bleomycin, etoposide, doxorubicin, cyclophosphamide, vincristine, procarbazine, prednisolone; CR-UK, Cancer Research UK; eBEACOPP, escalated BEACOPP; FIL, Fondazione Italiana Linfomi; GITIL, Gruppo Italiano Terapie Innovative nei Linfomi; HDC/ASCT, high dose chemotherapy with autologous hematopoietic stem cell transplantation; IGEV, ifosfamide, gemcitabine, etoposide, vinorelbine; iPET2, interim positron emission tomography scan after 2 cycles of ABVD; PFS, progression-free survival; SWOG, Southwest Oncology Group; Tx, therapy. 
total, 1334 patients with stage III or IV cHL were randomly assigned to the BV + AVD-arm $(n=664)$ and the ABVD arm $(n=670)$. The study met its primary endpoint, with the 2-year modified PFS being $82.1 \%$ in the BV+ AVD-arm vs $77.2 \%$ in the ABVD arm (HR: 0.77 [95\% CI: 0.60-0.98]; $p=0.04$ ) after a median follow-up duration of 24.6 months. However, the difference was modest, and the 95\% CI upper margin was near to 1 . Further, the OS was not significantly different between the two arms (2-year OS: 96.6\% [BV+AVD] vs 94.2\% [ABVD]).

Concerning toxicities, febrile neutropenia was observed in $19 \%$ in the BV+AVD arm and in $8 \%$ in the ABVD arm. In addition, 7 of 9 deaths in BV+AVD arm were associated with neutropenia. Therefore, primary prophylaxis with granulocyte colony-stimulating factor was recommended after the protocol amendment. Meanwhile, pulmonary toxicity was higher in the ABVD arm (2\% in BV + AVD vs $7 \%$ in ABVD). Based on the results, BV + AVD was approved for previously untreated advanced-stage $\mathrm{cHL}$ by the US FDA in 2018. However, although this large-scale multicenter phase III study met its primary endpoint, the clinical benefit of BV + AVD remains arguable, partly because of the following points. First is a complex endpoint that might have been affected by observer bias associated with the unblinded study design. Physicians knew whether their patients received $\mathrm{ABVD}$ or the new $\mathrm{BV}+\mathrm{AVD}$ treatment, and it could have impacted the decision on whether additional therapy was needed or not in patients with non-CR. In fact, among the 144 patients (65 with BV + AVD and 79 with ABVD) with Deauville 3-5 at the end-of-treatment PET scan, $14 \%$ (9 of 65 ) in the BV + AVD arm received subsequent therapy, whereas $28 \%$ (22 of 79 ) in the ABVD arm received such treatment. Second is the over-recruitment compared to the planned number of patients, and this might affect the relevance of $\mathrm{P}$ value. Initially, the study was designed to show a $7.5 \%$ difference of modified PFS $(82.5 \%$ vs $75 \%$, HR $0.67)$ at 3 years with 1,040 patients. However, the study was amended to evaluate the primary endpoint at 2 years, and 1,240 patients would have been needed to show an $8 \%$ difference ( $81 \%$ vs $73 \%$, HR 0.67). As such, 1,334 patients were enrolled in ECHELON-1. The actual HR was 0.77, but the difference of modified PFS was smaller than expected $(4.9 \%)$. Third is a relatively short follow-up duration, and fourth is controversial clinical benefit of BV + AVD in patients with stage III disease and elderly age.

To reveal the actual role of $\mathrm{BV}$ in the first-line setting, OS data with further long-term follow-up data are required.
While BV + AVD was compared against the international standard ABVD, escalated BEACOPP has also demonstrated superior efficacy in advanced-stage cHL when compared to ABVD. ${ }^{73-76}$ Escalated BEACOPP is not utilized internationally as a routine first-line therapy for advanced-stage cHL because of its high incidence of acute and/or late toxicities including second primary malignancies, and lack of benefit in terms of long-term clinical outcome when HDC/ASCT is planned at the relapsed setting. ${ }^{77}$ However, considering better initial tumor control, it is regarded as a standard of care for advanced-stage cHL in the German Hodgkin Study Group (GHSG). The investigators of GHSG are evaluating the incorporation of BV into a BEACOPP backbone. Two types of BV-containing regimens have been developed; BrECAPP and BrECADD regimens (BV, etoposide, cyclophosphamide, doxorubicin and procarbazine/prednisone or dacarbazine/dexamethasone). Because concomitant administration of bleomycin and BV increase the risk of pulmonary toxicity, bleomycin was replaced with $\mathrm{BV}$ in both regimens. Vincristine was also omitted because both vincristine and MMAE inhibit tubulin polymerization and may result in unacceptable neurotoxicity. In a randomized phase II study comparing BrECAPP and BrECADD, both regimens were equally effective. However, BrECADD was associated with a more favourable toxicity profile. ${ }^{78}$ Therefore, BrECADD was selected to be compared with the standard of care in the subsequent phase III study. Currently, a phase III study comparing BrECADD with escalated BEACOPP in patients with advanced-stage cHL is ongoing (HD21, NCT02661503).

\section{Untreated Advanced-Stage cHL in Elderly Patients}

Elderly patients with cHL (usually age over 60 years) account for $20 \%-30 \%$ of cHL. ${ }^{79}$ The elderly patients with cHL have poorer treatment outcome compared with that of younger patients. The 5-year PFS and OS rates are $30 \%-48 \%$ and $40 \%-58 \%$, respectively. ${ }^{80-84}$ This is partly because of treatment-related toxicities associated with comorbidities and the high incidence of bleomycin lung toxicity. As BV demonstrated high efficacy with minimal toxicities in relapsed/refractory patients with cHL, BV was tested in the front-line setting of elderly patients with $\mathrm{cHL}$ (Table 5). Forero-Torres et al tested single-agent BV in elderly patients with $\mathrm{cHL}^{85}$ Twenty-seven patients with untreated cHL aged 60 years or older were enrolled in this study. The ORR among the 26 efficacy-evaluable patients 
Table 5 Selected Studies of BV-Containing Regimen for Untreated Elderly Patients with cHL

\begin{tabular}{|l|l|l|l|l|l|}
\hline Treatment & Study Design & N & ORR & CR rate & PFS \\
\hline BV & Phase II & 27 & $92 \%$ & $73 \%$ & Median I0.5 months \\
BV + dacarbazine & Phase II & 22 & $100 \%$ & $62 \%$ & Median I7.9 months \\
BV + bendamustine & Phase II & 20 & $100 \%$ & $88 \%$ & Median not reached \\
Sequential BV and AVD & Phase II & 48 & $95 \%$ & $93 \%$ & $84 \%$ at 2 years \\
BV + nivolumab & Phase II & 18 & $100 \%$ & $72 \%$ & ND \\
\hline
\end{tabular}

Abbreviations: AVD, doxorubicin, vinblastine, dacarbazine; BV, brentuximab vedotin; CR, complete response; ND, no available data; ORR, objective response rate; PFS, progression-free survival.

was $92 \%$ (24 of 26$)$, with $73 \%$ of patients (19 of 26$)$ achieving CR. However, the median PFS was only 10.5 months. Subsequently, frontline BV in combination with dacarbazine or bendamustine was tested in a phase II study. ${ }^{86}$ In this study, 22 patients received $1.8 \mathrm{mg} / \mathrm{kg} \mathrm{BV}$ and $375 \mathrm{mg} / \mathrm{m}^{2}$ dacarbazine for up to 12 cycles, and 20 more patients received $1.8 \mathrm{mg} / \mathrm{kg} \mathrm{BV}$ plus 90 (or 70) $\mathrm{mg} /$ $\mathrm{m}^{2}$ bendamustine for up to 6 cycles. All the patients in both treatment regimens achieved objective responses, but the $\mathrm{CR}$ rate was higher in patients treated with bendamustine-based regimen $(62 \%$ in $\mathrm{BV}+$ dacarbazine vs $88 \%$ in $\mathrm{BV}+$ bendamustine). Nevertheless, despite encouraging efficacy, patients treated with $\mathrm{BV}+$ bendamustine tended to experience more severe adverse events, and the regimen was determined to be too toxic in this population.

Another approach for using BV with conventional chemotherapy in elderly patients is a sequential combination. A subgroup analysis of elderly patients treated in the ECHELON-1 study did not find the superiority of concurrent combination of BV-AVD over ABVD with respect to both PFS and modified PFS. Further, the incidence of febrile neutropenia $(\mathrm{FN})$ was higher in the $\mathrm{BV}+\mathrm{AVD}$ arm than that in the ABVD arm (37\% vs $17 \%) .{ }^{87}$ To reduce the toxicities associated with concurrent combination of BV with cytotoxic chemotherapy, Evens et al conducted a phase II study of a sequential combination of BV and AVD for elderly patients with untreated $\mathrm{cHL}{ }^{88}$ The study treatment comprised 2 cycles of lead-in BV (1.8 mg/kg, 21-day cycle) followed by 6 cycles of AVD and 4 subsequent cycles of consolidation BV. In total, of the 48 patients enrolled, 42 patients were evaluable for the efficacy. The ORR was $95 \%$ ( 40 of 42 ), and the CR rate was $93 \%$ (39 of 42). Of note, the incidence of FN was only $8 \%$. Although this was a small-scale, single-arm study, the results show that sequential $\mathrm{BV}$ combination is more tolerable with sufficient efficacy in older patients with cHL.

BV plus nivolumab is thought to be an attractive treatment option in this setting. Recently, results of a phase II study of BV plus nivolumab in patients with classic Hodgkin lymphoma aged $\geq 60$ years were reported. ${ }^{89}$ In total, 21 patients received BV (1.8 $\mathrm{mg} / \mathrm{kg})$ and nivolumab $(3 \mathrm{mg} / \mathrm{kg})$ on day 1 of each 21-day cycle for up to 16 cycles. The median age was 72 years (range, 60-88); the majority had ECOG-PS $0-1(95 \%)$ and stage III-IV disease (77\%). Among the 18 response-evaluable patients, all achieved objective responses, including 13 patients $(72 \%)$ with CR. The median duration of the response was not yet reached, and the maximum duration of the response was 22 months and ongoing. The most common treatment-related AEs of any grade were fatigue $(48 \%)$, peripheral sensory neuropathy (38\%), diarrhea, IRR, and pyrexia (24\% each). The most common AEs of grade 3 or higher were lipase increases (19\%) and peripheral motor neuropathy (14\%).

Considering the encouraging efficacy and tolerability of $\mathrm{BV}+$ nivolumab, it might be a potential treatment option in this setting, especially for patients who are unfit for cytotoxic chemotherapy. Validation in a large sample of patients with longer follow-up data is warranted.

\section{BV in Combination with Chemotherapy for Early-Stage Untreated cHL}

As most early-stage cHL can be cured with chemoradiotherapy, determining methods to reduce the risk of late toxicities such as second primary malignancy or cardiovascular toxicity is a major purpose of clinical development in this population. The late toxicities are mostly associated with radiotherapy. Therefore, several treatment strategies to omit radiotherapy have been evaluated. The H10 trial conducted by EORTC/LYSA/FIL and the RAPID trial conducted by a UK study group evaluated a PETadapted strategy to omit radiotherapy in the PET-negative population. $^{90-92}$ However, both studies failed to show noninferiority of omission of radiotherapy.

The GHSG previously demonstrated that in early-stage $\mathrm{cHL}$ patients without unfavorable risk factors (so-called 


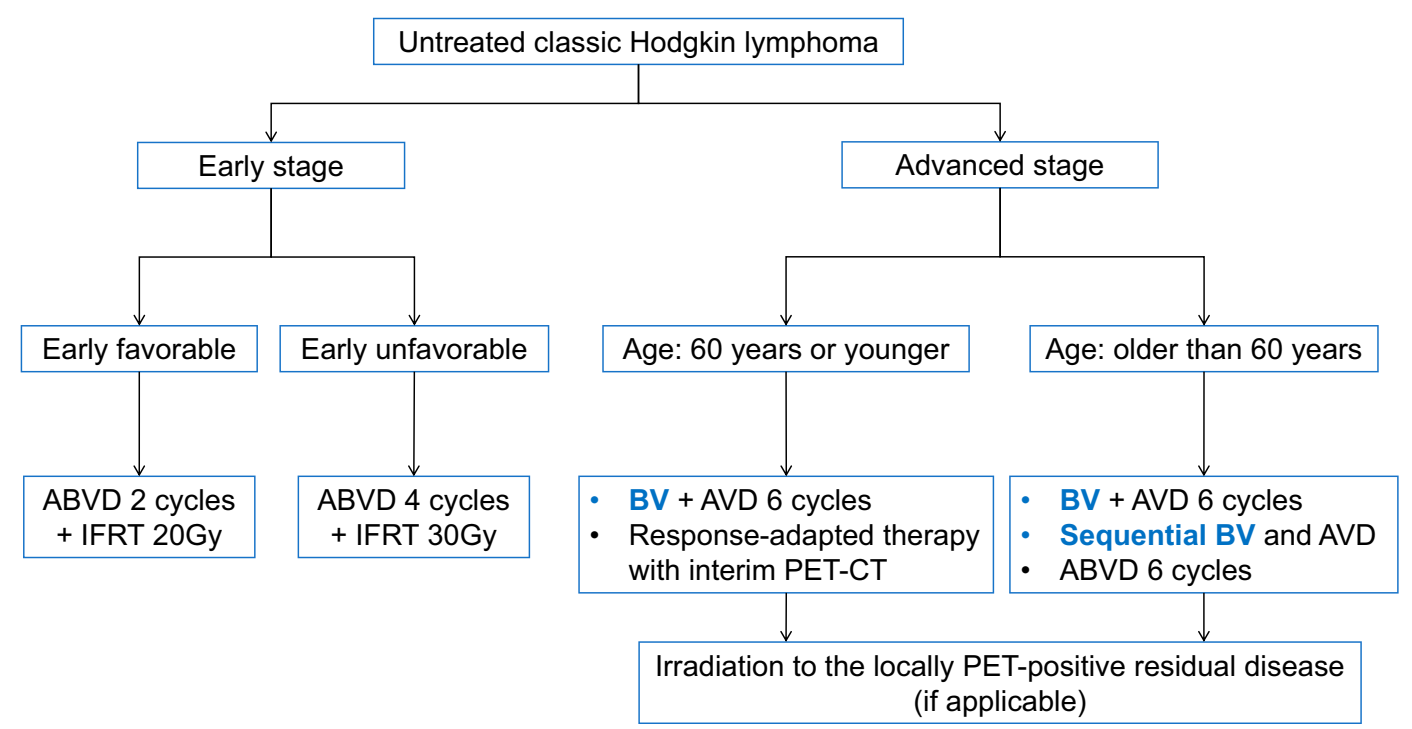

Figure 4 Current treatment strategy for untreated classic Hodgkin lymphoma.

Abbreviations: ABVD, doxorubicin, bleomycin, vinblastine, and dacarbazine; AVD, doxorubicin, bleomycin, vinblastine, and dacarbazine; BV brentuximab vedotin; IFRT, involved-field radiotherapy; PET-CT, positron emission tomography-computed tomography.

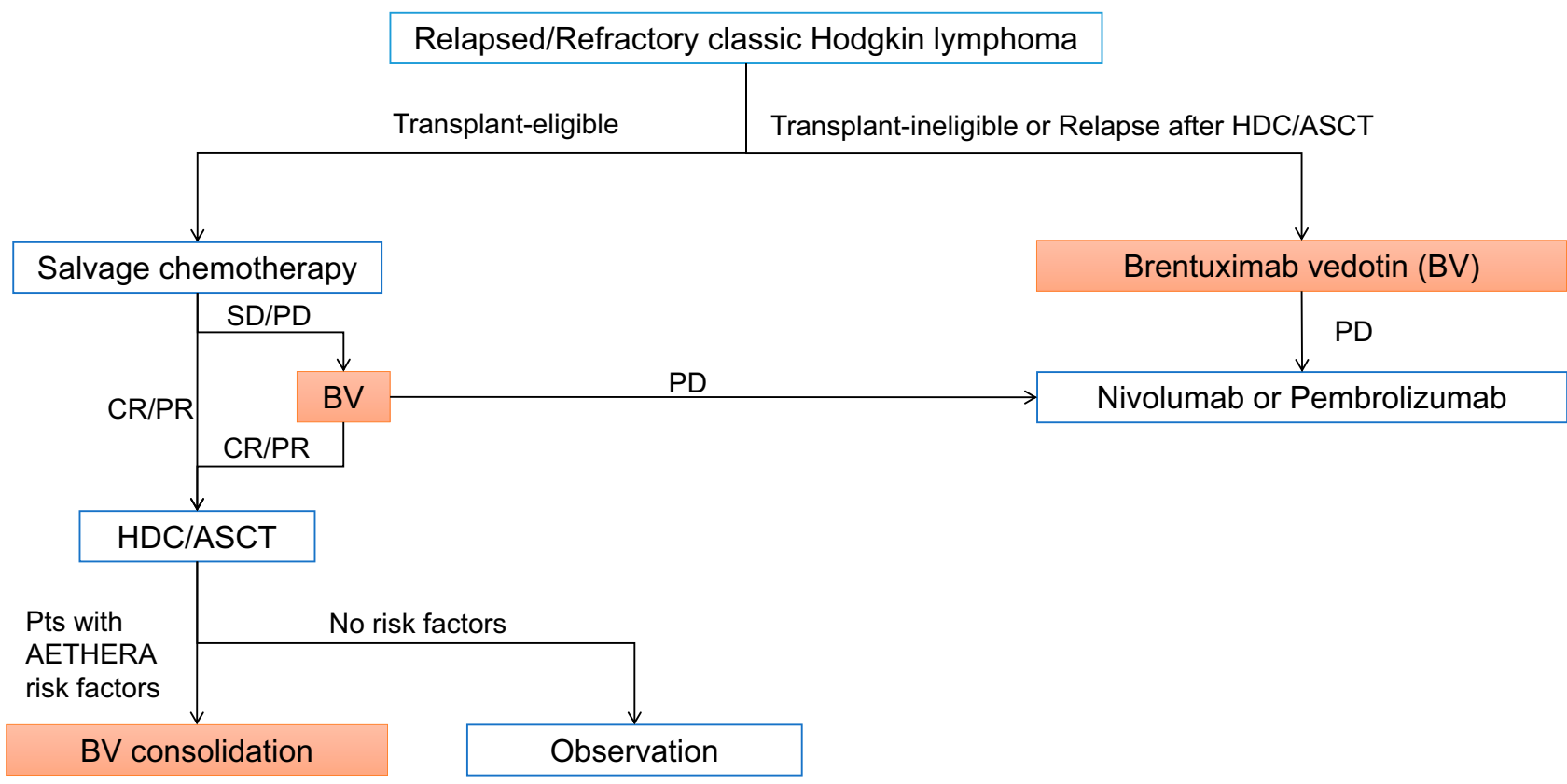

Figure 5 Current treatment strategy for relapsed/refractory classic Hodgkin lymphoma.

Abbreviations: BV, brentuximab vedotin; CR, complete response; HDC/ASCT, high-dose chemotherapy with autologous stem cell transplantation; PD, progressive disease; $\mathrm{PR}$, partial response; SD, stable disease.

"early-favorable"), the number of cycles of ABVD can be reduced with preserving efficacy from 4 to 2 cycles and the dose of radiotherapy can also be reduced (30 to $20 \mathrm{~Gy}){ }^{93,94}$ Subsequently, they have tested to omit radiotherapy for those who demonstrated PET-negative scan after 2 cycles of ABVD in patients with early-favorable cHL. However, noninferiority has not been confirmed even in this population (the 5-year PFS was $93.4 \%$ for those who received ABVD followed by radiotherapy vs $86.1 \%$ in ABVD alone). ${ }^{95}$

Recently, Abramson et al evaluated BV + AVD without consolidative radiotherapy in patients with early-stage nonbulky cHL. ${ }^{96}$ In this phase II study, 34 patients with earlystage cHL were enrolled. The best CR rate was $100 \%$, and the 3 -year PFS and OS were 94\% and 97\%, respectively, with 


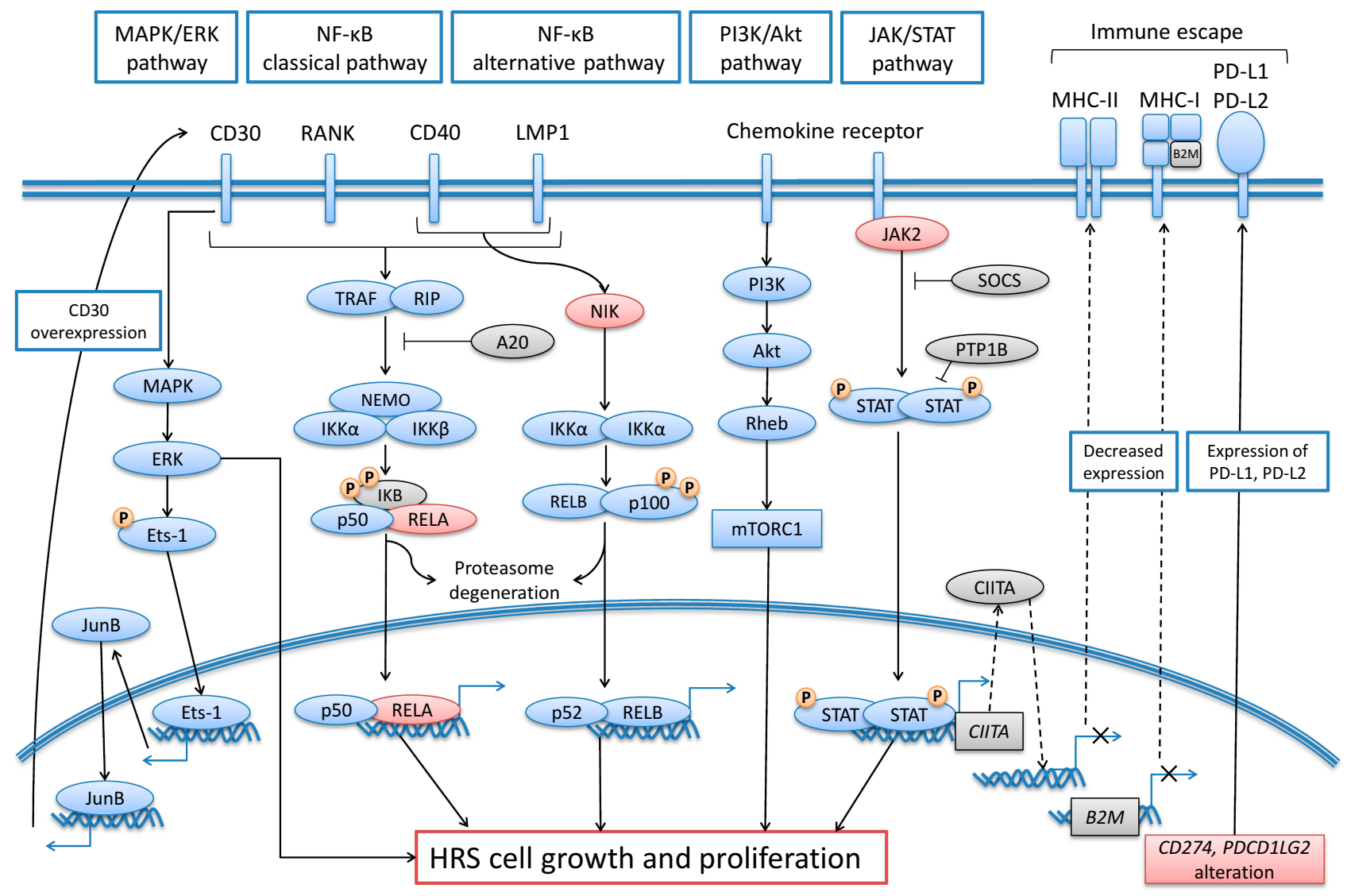

Figure 6 Signaling pathways and genomic alterations in Hodgkin Reed Sternberg cell Activating mutations are highlighted in red, and loss-of-function mutations are highlighted in gray.

Abbreviations: B2M, beta-2 microglobulin; CIITA, class II major histocompatibility complex transactivator; ERK, extracellular signal-regulated kinase; HLA, major histocompatibility complex; IKK, I kappa kinase; JAK, Janus kinase; LMPI, latent membrane protein I; MAPK, mitogen-activated protein kinase; mTORCI, mammalian

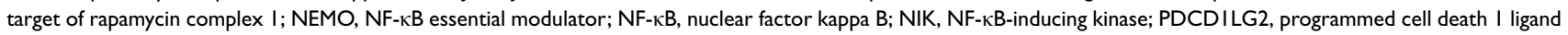
2; PD-LI/-L2, programmed cell death-ligand I/-ligand 2; PI3K, phosphatidylinositol 3-kinase; PTPIB, protein tyrosine phosphatase IB; RANK, receptor activator of nuclear factor kappa B; RIP, receptor interacting protein; Rheb, Ras homolog enriched in brain; SOCS, suppressor of cytokine signaling; STAT, signal transducers and activator of transcription; TRAF, TNF receptor associated factor.

a median follow-up duration of 38 months. The results indicate that BV + AVD without consolidative radiotherapy yields similar benefit with that of chemoradiotherapy. However, it remains unclear whether radiotherapy can be omitted by using BV-containing chemotherapy in early-stage patients because this was a small-scale, single-arm phase II study with a relatively short follow-up duration. As early-stage $\mathrm{cHL}$ is a highly curable disease when treated with standard chemoradiotherapy, omission of radiotherapy should be carefully evaluated. For the treatment course, radiotherapy should never be omitted in the first-line treatment for early-stage cHL outside the clinical trials.

\section{Resistance Mechanisms Against BV}

The actual mechanism by which cHL patients become refractory to $\mathrm{BV}$ remains unclear. In ALCL patients, CD30 downregulation was observed when exposed to
BV both in vitro and in vivo. ${ }^{97,98}$ However, CD30 expression remains preserved in patients with BV-refractory cHL. $^{99}$ Instead, MMAE resistance and upregulation of multi drug resistance mutation 1 (MDR1), which pumps MMAE out of the tumor cells, are thought to play major roles in the refractory mechanism of $\mathrm{cHL}$ patients to $\mathrm{BV} .^{97}$ Currently, a phase I study of BV in combination with cyclosporine or verapamil, which are substrates for MDR1 and may prevent the export of MMAE by overwhelming the transporter, is ongoing (NCT03013933).

\section{Conclusions and Future Directions}

Current treatment strategies for $\mathrm{cHL}$ and the role of BV are summarized in Figures 4 and 5. BV plays important roles both in the relapsed/refractory and in front-line settings.

Among patients who experience relapsed/refractory $\mathrm{cHL}$ after HDC/ASCT, single-agent $\mathrm{BV}$ has demonstrated 
Table 6 Selected Targeted Therapies for Relapsed/Refractory Classic Hodgkin Lymphoma

\begin{tabular}{|c|c|c|c|c|c|}
\hline Agent & Target & Study Design & Number of Patients & ORR & Reference \\
\hline Bortezomib & $N F-\kappa B$ & Phase II & 30 & $0 \%$ & Blum et al Leuk Lymphoma $2007^{103}$ \\
\hline SBI518 & JAK2 & Phase I & 14 & $0 \%$ & Younes et al J Clin Oncol 2012 $2^{104}$ \\
\hline Ruxolitinib & JAKI/2 & Phase II & 32 & 18.8 & Van Den Neste et al Haematologica $2018^{105}$ \\
\hline Everolimus & mTOR & Phase II & 19 & $47 \%$ & Johnston et al Am J Hematol $2010^{106}$ \\
\hline Idelalisib & $\mathrm{PI} 3 \mathrm{~K} \delta$ & Phase II & 25 & $20 \%$ & Gopal et al Ann Oncol $2017^{107}$ \\
\hline MK2206 & AKT & Phase II & 25 & $23 \%$ & Oki et al $\mathrm{Br} J$ Haematol $2015^{108}$ \\
\hline Panobinostat & HDAC & Phase II & 129 & $27 \%$ & Younes et al J Clin Oncol $2012^{109}$ \\
\hline Mocetinostat & HDAC & Phase II & 23 (85 mg cohort) & $26 \%$ & Younes et al Lancet Oncol $201 I^{110}$ \\
\hline Entinostat & HDAC & Phase II & 49 & $12 \%$ & Batlevi et al Haematologica $2016^{111}$ \\
\hline Resminostat & HDAC & Phase II & 37 & $34 \%$ & Walewski et al Leuk Lymphoma $2019^{1 / 2}$ \\
\hline
\end{tabular}

Abbreviations: AKT, protein kinase B; HDAC, histone deacetylase; JAK, Janus kinase; mTOR, mammalian target of rapamycin; NF-KB, nuclear factor kappa B; PI3K, phosphatidylinositol 3-kinase.

substantial efficacy with a favorable toxicity profile. However, more than half of patients experience disease progression and there is clearly room for further improvement.

$\mathrm{BV}$ in combination with immune checkpoint inhibitors is actively being developed in this setting. The Eastern Cooperative Oncology Group (ECOG) and the American College of Radiology Imaging Network (ACRIN) Cancer Research Group conducted a phase I/II study (E4412) comparing two doublet regimens and one triplet regimens: BV + ipilimumab (anti-cytotoxic T lymphocyte antigen 4 [CTLA4] antibody), BV + nivolumab, and $\mathrm{BV}+$ nivolumab + ipilimumab in patients with relapsed/refractory cHL. ${ }^{100}$ The $\mathrm{ORR} / \mathrm{CR}$ rates in these regimens were $67 \% / 55 \%, 95 \% / 65 \%$, and $95 / 79 \%$, respectively. Despite the highest efficacy identified for the triplet regimen, 4 of 5 DLTs in this study were observed in the triplet arm including grade 4 diabetic ketoacidosis, hyperglycemia, grade 3 transaminitis, and grade 4 graft versus host disease (in a patient with a previous history of allogeneic HSCT). Currently, a randomized phase II part comparing a BV-nivolumab doublet regimen with triplet regimen is ongoing.

BV combined with small-molecule treatment is another expected approach. Recent advances in basic research have revealed molecular pathogenesis of $\mathrm{cHL}$ (Figure 6) ${ }^{101,102}$ leading to the clinical development of several targeted small molecules (Table 6). ${ }^{103-112}$ However, the development of these small molecules fell out of favor because of their moderate efficacy with singleagent use. Currently, the combination of BV and/or immune checkpoint inhibitors with small molecules is being tested in early phase trials.

In the second-line setting, seeking a novel optimal salvage regimen before HDC/ASCT is warranted. Based on several single-arm studies of BV-containing cytotoxic regimens, incorporation of $\mathrm{BV}$ into this setting appears to be reasonable. Further, conventional-cytotoxic-free strategies, such as PET-adapted sequential BV-salvage and BV in combination with immune checkpoint inhibitors are actively being tested. However, careful evaluation in a randomized trial with long-term follow-up is warranted to further evaluate the role of $\mathrm{BV}$ in this setting.

The role of BV in the first-line setting may be more controversial than that in other settings. Despite positive results of the ECHELON-1 study, the actual clinical benefit of BV-AVD remains arguable. The final results should help to determine whether the curve separation will be consistent with longer follow-up. In addition, a randomized phase III study comparing AVD in combination with nivolumab with BV-AVD in patients with untreated advanced-stage cHL is ongoing (SWOG S1826, NCT03907488). The results of this study might change the role of BV in this setting in the future.

Introduction of BV into the first-line setting will make the application of previous evidence of BV for relapsed/ refractory cHL difficult. However, as increasing data support the efficacy of BV re-treatment, ${ }^{113,114}$ patients who initially respond to $\mathrm{BV}$ and subsequently experience relapse may be considered for $\mathrm{BV}$-containing treatment strategy.

Considering the high efficacy and low toxicity of BV, it is a suitable agent for the treatment of elderly patients with cHL, particularly in the front-line setting. Although Evens et al demonstrated the safety and efficacy of sequential BV with AVD, the strategy is applicable only to patients who are fit for an anthracycline-containing regimen. Further studies to optimize the use of BV in this population, including $\mathrm{BV}+$ nivolumab is expected. 
In conclusion, $\mathrm{BV}$ has opened a new horizon for the management of cHL and has provided a novel treatment paradigm since the first FDA approval. However, there remains several arguable discussion points, especially in the first-line setting. Further accumulation of data with well-designed clinical trials is warranted to identify the exact role of BV in our daily clinical practice.

\section{Abbreviations}

ABVD, doxorubicin, bleomycin, vinblastine, and dacarbazine; AE, adverse events; ALCL, anaplastic large cell lymphoma; ASCT, autologous stem cell transplantation; APC, antigen presenting cell; BEACOPP, bleomycin, etoposide, doxorubicin, cyclophosphamide, vincristine, procarbazine, and prednisolone; $\mathrm{BV}$, brentuximab vedotin; $\mathrm{CAC} 10$, chimeric anti-CD30 monoclonal antibody; cHL, Classic Hodgkin lymphoma; $\mathrm{CMR}$, complete metabolic response; $\mathrm{CR}$, complete response; CTLA-4, cytotoxic T lymphocyte antigen 4; DHAP, dexamethasone, cytarabine, and cisplatin; DLT, dose-limiting toxicities; ER, endoplasmic reticulum; ESHAP, etoposide methylprednisolone, cytarabine, and cisplatin; BRESHAP, ESHAP in combination with $\mathrm{BV}$; FN, febrile neutropenia; FDA, Food and Drug Administration; HR, hazard ratio; HDC, high-dose chemotherapy; ICE, ifosfamide, carboplatin, etoposide; IrAE, immune-related adverse events; IRR, infusion-related reaction; iPET2, interim PET-CT performed after 2 cycles; MTD, maximum-tolerated dose; MMAE, monomethyl auristatin E; MDR1, multidrug resistance mutation 1; ORR, objective response rate; OS, overall survival; PFS, progression-free survival; RIP, ribosome-inactivating proteins.

\section{Disclosure}

SM received honoraria from Takeda, Novartis, Eisai, and Celgene. DM received honoraria from Ono Pharmaceutical, Celgene, Takeda, Janssen, Eisai, Chugai Pharma, Kyowa Hakko Kirin, Zenyaku Kogyo, Bristol-Myers Squibb, Synmosa Biopharma Corporation, Nippon Shinyaku, and research funding from Merck, Amgen Astellas BioPharma, Astellas Pharma, Sanofi, Celgene, Novartis Pharma, BristolMyers Squibb, Janssen, Ono Pharmaceutical, Otsuka, Chugai Pharma, and Takeda. KT received honoraria from Zenyaku Kogyo, Eisai, Takeda, Mundipharma, HUYA Bioscience International, Kyowa Hakko Kirin, Celgene, Chugai Pharma, Ono Pharmaceutical, Yakult, Daiichi Sankyo, Bristol-Meyers Squibb, Meiji Seika Kaisha, Solacia Pharma, Verastem, and serving consulting or advisory role in Celgene, Zenyaku Kogyo, Huya Bioscience, Daiichi Sankyo, Takeda, Mundipharma, Ono
Pharmaceutical, and received research funding from Chugai Pharma, Kyowa Hakko Kirin, Ono Pharmaceutical, Celgene, Janssen, Eisai, Mundi Pharma, Takeda, and Abbvie. The authors report no other conflicts of interest in this work.

\section{References}

1. Eichenauer DA, Engert A. Advances in the treatment of Hodgkin lymphoma. Int J Hematol. 2012;96(5):535-543. doi:10.1007/ s12185-012-1199-2

2. Makita S, Maruyama D, Maeshima AM, et al. Clinical features and outcomes of 139 Japanese patients with Hodgkin lymphoma. Int J Hematol. 2016;104(2):236-244. doi:10.1007/s12185-0162007-1

3. Minn AY, Riedel E, Halpern J, et al. Long-term outcomes after high dose therapy and autologous haematopoietic cell rescue for refractory/relapsed Hodgkin lymphoma. Br J Haematol. 2012;159 (3):329-339. doi:10.1111/bjh.12038

4. Arai S, Fanale M, DeVos S, et al. Defining a Hodgkin lymphoma population for novel therapeutics after relapse from autologous hematopoietic cell transplant. Leuk Lymphoma. 2013;54 (11):2531-2533. doi:10.3109/10428194.2013.798868

5. Schwab U, Stein H, Gerdes J, et al. Production of a monoclonal antibody specific for Hodgkin and Sternberg-Reed cells of Hodgkin's disease and a subset of normal lymphoid cells. Nature. 1982;299(5878):65-67. doi:10.1038/299065a0

6. Stein H, Gerdes J, Schwab U, et al. Identification of Hodgkin and Sternberg-reed cells as a unique cell type derived from a newly-detected small-cell population. Int J Cancer. 1982;30 (4):445-459. doi:10.1002/ijc.2910300411

7. Watanabe M, Itoh $\mathrm{K}$, Togano $\mathrm{T}$, et al. Ets-1 activates overexpression of JunB and CD30 in Hodgkin's lymphoma and anaplastic large-cell lymphoma. Am J Pathol. 2012;180(2):831-838. doi:10.1016/j.ajpath.2011.10.007

8. Horie R, Watanabe T. CD30: expression and function in health and disease. Semin Immunol. 1998;10(6):457-470. doi:10.1006/ smim.1998.0156

9. Bossard C, Dobay MP, Parrens M, et al. Immunohistochemistry as a valuable tool to assess CD30 expression in peripheral T-cell lymphomas: high correlation with mRNA levels. Blood. 2014;124 (19):2983-2986. doi:10.1182/blood-2014-07-584953

10. Sabattini E, Pizzi M, Tabanelli V, et al. CD30 expression in peripheral T-cell lymphomas. Haematologica. 2013;98(8):e81e82. doi:10.3324/haematol.2013.084913

11. Ito Y, Makita S, Tobinai K. Development of new agents for peripheral T-cell lymphoma. Expert Opin Biol Ther. 2019;19 (3):197-209. doi:10.1080/14712598.2019.1572746

12. Horwitz S, O’Connor OA, Pro B, et al. Brentuximab vedotin with chemotherapy for CD30-positive peripheral T-cell lymphoma (ECHELON-2): a global, double-blind, randomised, Phase 3 trial. Lancet. 2019;393(10168):229-240. doi:10.1016/S01406736(18)32984-2

13. Higuchi M, Matsuda $\mathrm{T}$, Mori $\mathrm{N}$, et al. Elevated expression of CD30 in adult T-cell leukemia cell lines: possible role in constitutive NF-kappaB activation. Retrovirology. 2005;2:29. doi:10.1186/1742-4690-2-29

14. Pongpruttipan T, Sukpanichnant S, Assanasen T, et al. Extranodal NK/T-cell lymphoma, nasal type, includes cases of natural killer cell and $\alpha \beta, \gamma \delta$, and $\alpha \beta / \gamma \delta$ T-cell origin: a comprehensive clinicopathologic and phenotypic study. Am J Surg Pathol. 2012;36 (4):481-499. doi:10.1097/PAS.0b013e31824433d8

15. Makita S, Tobinai K. Clinical features and current optimal management of natural killer/T-cell lymphoma. Hematol Oncol Clin North Am. 2017;31(2):239-253. doi:10.1016/j.hoc.2016.11.007 
16. Hu S, Xu-Monette ZY, Balasubramanyam A, et al. CD30 expression defines a novel subgroup of diffuse large B-cell lymphoma with favorable prognosis and distinct gene expression signature: a report from the International DLBCL Rituximab-CHOP Consortium Program Study. Blood. 2013;121(14):2715-2724. doi:10.1182/blood-2012-10-461848

17. Campuzano-Zuluaga G, Cioffi-Lavina M, Lossos IS, ChapmanFredricks JR. Frequency and extent of CD30 expression in diffuse large B-cell lymphoma and its relation to clinical and biologic factors: a retrospective study of 167 cases. Leuk Lymphoma. 2013;54(11):2405-2411. doi:10.3109/10428194.2013.778407

18. Slack GW, Steidl C, Sehn LH, Gascoyne RD. CD30 expression in de novo diffuse large B-cell lymphoma: a population-based study from British Columbia. Br J Haematol. 2014;167(5):608-617. doi:10.1111/bjh.13085

19. Jacobsen ED, Sharman JP, Oki Y, et al. Brentuximab vedotin demonstrates objective responses in a Phase 2 study of relapsed/ refractory DLBCL with variable CD30 expression. Blood. 2015;125(9):1394-1402. doi:10.1182/blood-2014-09-598763

20. Durkop H, Foss HD, Eitelbach F, et al. Expression of the CD30 antigen in non-lymphoid tissues and cells. J Pathol. 2000;190 (5):613-618. doi:10.1002/(SICI)1096-9896(200004)190:5<613:: AID-PATH559 $>3.0 . \mathrm{CO} ; 2-0$

21. Ansell SM, Horwitz SM, Engert A, et al. Phase I/II study of an anti-CD30 monoclonal antibody (MDX-060) in Hodgkin's lymphoma and anaplastic large-cell lymphoma. J Clin Oncol. 2007;25(19):2764-2769. doi:10.1200/JCO.2006.07.8972

22. Forero-Torres A, Leonard JP, Younes A, et al. A phase II study of SGN-30 (anti-CD30 mAb) in Hodgkin lymphoma or systemic anaplastic large cell lymphoma. Br J Haematol. 2009;146 (2):171-179. doi:10.1111/j.1365-2141.2009.07740.x

23. Falini B, Bolognesi A, Flenghi L, et al. Response of refractory Hodgkin's disease to monoclonal anti-CD30 immunotoxin. Lancet. 1992;339(8803):1195-1196. doi:10.1016/0140-6736(92) 91135-U

24. Matthey B, Borchmann P, Schnell R, et al. Metalloproteinase inhibition augments antitumor efficacy of the anti-CD30 immunotoxin $\mathrm{Ki}-3(\mathrm{scFv})-\mathrm{ETA}^{\prime}$ against human lymphomas in vivo. Int J Cancer. 2004;111(4):568-574. doi:10.1002/ijc.20278

25. Schnell R, Staak O, Borchmann P, et al. A phase I study with an anti-CD30 ricin A-chain immunotoxin (Ki-4.dgA) in patients with refractory CD30+ Hodgkin's and non-Hodgkin's lymphoma. Clin Cancer Res. 2002;8(6):1779-1786.

26. Doronina SO, Toki BE, Torgov MY, et al. Development of potent monoclonal antibody auristatin conjugates for cancer therapy. Nat Biotechnol. 2003;21(7):778-784. doi:10.1038/nbt832

27. Francisco JA, Cerveny CG, Meyer DL, et al. cAC10-vcMMAE, an anti-CD30-monomethyl auristatin E conjugate with potent and selective antitumor activity. Blood. 2003;102(4):1458-1465. doi:10.1182/blood-2003-01-0039

28. King HD, Dubowchik GM, Mastalerz H, et al. Monoclonal antibody conjugates of doxorubicin prepared with branched peptide linkers: inhibition of aggregation by methoxy triethylene glycol chains. J Med Chem. 2002;45(19):4336-4343. doi:10.1021/ jm020149g

29. Younes A, Bartlett NL, Leonard JP, et al. Brentuximab vedotin (SGN-35) for relapsed CD30-positive lymphomas. $N$ Engl J Med. 2010;363(19):1812-1821. doi:10.1056/NEJMoa1002965

30. Fanale MA, Forero-Torres A, Rosenblatt JD, et al. A phase I weekly dosing study of brentuximab vedotin in patients with relapsed/refractory CD30-positive hematologic malignancies. Clin Cancer Res. 2012;18(1):248-255. doi:10.1158/1078-0432. CCR-11-1425
31. Younes A, Gopal AK, Smith SE, et al. Results of a pivotal phase II study of brentuximab vedotin for patients with relapsed or refractory Hodgkin's lymphoma. J Clin Oncol. 2012;30 (18):2183-2189. doi:10.1200/JCO.2011.38.0410

32. Chen R, Gopal AK, Smith SE, et al. Five-year survival and durability results of brentuximab vedotin in patients with relapsed or refractory Hodgkin lymphoma. Blood. 2016;128 (12):1562-1566. doi:10.1182/blood-2016-02-699850

33. Schmitz N, Pfistner B, Sextro M, et al. Aggressive conventional chemotherapy compared with high-dose chemotherapy with autologous haemopoietic stem-cell transplantation for relapsed chemosensitive Hodgkin's disease: a randomised trial. Lancet. 2002;359 (9323):2065-2071. doi:10.1016/S0140-6736(02)08938-9

34. Linch DC, Winfield D, Goldstone AH, et al. Dose intensification with autologous bone-marrow transplantation in relapsed and resistant Hodgkin's disease: results of a BNLI randomised trial. Lancet. 1993;341(8852):1051-1054. doi:10.1016/0140-6736(93)92411-L

35. Diehl V, Stein H, Hummel M, Zollinger R, Connors JM. Hodgkin's lymphoma: biology and treatment strategies for primary, refractory, and relapsed disease. Hematology Am Soc Hematol Educ Program. 2003;2003(1):225-247. doi:10.1182/ asheducation-2003.1.225

36. Moskowitz $\mathrm{CH}$, Nademanee A, Masszi $\mathrm{T}$, et al. Brentuximab vedotin as consolidation therapy after autologous stem-cell transplantation in patients with Hodgkin's lymphoma at risk of relapse or progression (AETHERA): a randomised, double-blind, placebo-controlled, phase 3 trial. Lancet. 2015;385 (9980):1853-1862. doi:10.1016/S0140-6736(15)60165-9

37. Moskowitz CH, Walewski J, Nademanee A, et al. Five-year PFS from the AETHERA trial of brentuximab vedotin for Hodgkin lymphoma at high risk of progression or relapse. Blood. 2018;132 (25):2639-2642. doi:10.1182/blood-2018-07-861641

38. Moskowitz AJ, Yahalom J, Kewalramani $\mathrm{T}$, et al. Pretransplantation functional imaging predicts outcome following autologous stem cell transplantation for relapsed and refractory Hodgkin lymphoma. Blood. 2010;116(23):4934-4937. doi:10. 1182/blood-2010-05-282756

39. Devillier R, Coso D, Castagna L, et al. Positron emission tomography response at the time of autologous stem cell transplantation predicts outcome of patients with relapsed and/or refractory Hodgkin's lymphoma responding to prior salvage therapy. Haematologica. 2012;97(7):1073-1079. doi:10.3324/haematol.20 11.056051

40. Akhtar S, Al-Sugair AS, Abouzied M, et al. Pre-transplant FDG-PETbased survival model in relapsed and refractory Hodgkin's lymphoma: outcome after high-dose chemotherapy and auto-SCT. Bone Marrow Transplant. 2013;48(12):1530-1536. doi:10.1038/bmt.2013.88

41. Josting A, Rudolph C, Reiser M, et al. Time-intensified dexamethasone/cisplatin/cytarabine: an effective salvage therapy with low toxicity in patients with relapsed and refractory Hodgkin's disease. Ann Oncol. 2002;13(10):1628-1635. doi:10.1093/annonc/mdf221

42. Moskowitz CH, Nimer SD, Zelenetz AD, et al. A 2-step comprehensive high-dose chemoradiotherapy second-line program for relapsed and refractory Hodgkin disease: analysis by intent to treat and development of a prognostic model. Blood. 2001;97 (3):616-623. doi:10.1182/blood.V97.3.616

43. Aparicio J, Segura A, Garcerá S, et al. ESHAP is an active regimen for relapsing Hodgkin's disease. Ann Oncol. 1999;10 (5):593-595. doi:10.1023/A:1026454831340

44. Bartlett NL, Niedzwiecki D, Johnson JL, et al. Gemcitabine, vinorelbine, and pegylated liposomal doxorubicin (GVD), a salvage regimen in relapsed Hodgkin's lymphoma: CALGB 59804. Ann Oncol. 2007;18(6):1071-1079. doi:10.1093/annonc/ mdm090 
45. Kuruvilla J, Nagy T, Pintilie M, et al. Similar response rates and superior early progression-free survival with gemcitabine, dexamethasone, and cisplatin salvage therapy compared with carmustine, etoposide, cytarabine, and melphalan salvage therapy prior to autologous stem cell transplantation for recurrent or refractory Hodgkin lymphoma. Cancer. 2006;106(2):353-360. doi:10.1002/ cncr.21587

46. Moskowitz AJ, Schöder H, Yahalom J, et al. PET-adapted sequential salvage therapy with brentuximab vedotin followed by augmented ifosamide, carboplatin, and etoposide for patients with relapsed and refractory Hodgkin's lymphoma: a non-randomised, open-label, single-centre, phase 2 study. Lancet Oncol. 2015;16 (3):284-292. doi:10.1016/S1470-2045(15)70013-6

47. Chen R, Palmer JM, Martin P, et al. Results of a multicenter phase II trial of brentuximab vedotin as second-line therapy before autologous transplantation in relapsed/refractory Hodgkin lymphoma. Biol Blood Marrow Transplant. 2015;21 (12):2136-2140. doi:10.1016/j.bbmt.2015.07.018

48. Garcia-Sanz R, Sureda A, de la Cruz F, et al. Brentuximab vedotin and ESHAP is highly effective as second-line therapy for Hodgkin lymphoma patients (long-term results of a trial by the Spanish GELTAMO Group). Ann Oncol. 2019;30(4):612-620. doi:10.1093/annonc/mdz009

49. Hagenbeek A, Mooij H, Zijlstra J, et al. Phase I dose-escalation study of brentuximab-vedotin combined with dexamethasone, high-dose cytarabine and cisplatin, as salvage treatment in relapsed/refractory classical Hodgkin lymphoma: the HOVON/ LLPC Transplant BRaVE study. Haematologica. 2019;104(4): e151-e153. doi:10.3324/haematol.2018.196899

50. Hagenbeek A, Zijlstra J, Plattel WJ, et al. Combining brentuximab vedotin with DHAP as salvage treatment in relapsed/refractory Hodgkin lymphoma: the phase II HOVON/LLPC transplant BRaVE study. Blood. 2018;132(Suppl_1):2923. doi:10.1182/ blood-2018-99-112235

51. Cassaday RD, Fromm J, Cowan AJ, et al. Radiographic and high-throughput sequencing (HTS)-based response assessment after brentuximab vedotin (BV) plus ifosfamide, carboplatin, and etoposide (ICE) for relapsed/refractory (Rel/Ref) classical Hodgkin lymphoma (cHL): updated results of a phase I/II trial. Blood. 2017;130(Suppl_1):2806.

52. LaCasce AS, Bociek RG, Sawas A, et al. Brentuximab vedotin plus bendamustine: a highly active first salvage regimen for relapsed or refractory Hodgkin lymphoma. Blood. 2018;132 (1):40-48. doi:10.1182/blood-2017-11-815183

53. Cole PD, McCarten KM, Pei Q, et al. Brentuximab vedotin with gemcitabine for paediatric and young adult patients with relapsed or refractory Hodgkin's lymphoma (AHOD1221): a Children's Oncology Group, multicentre single-arm, Phase 1-2 trial. Lancet Oncol. 2018;19(9):1229-1238. doi:10.1016/S1470-2045(18)30426-1

54. Labrador J, Cabrero-Calvo M, Pérez-López E, et al. ESHAP as salvage therapy for relapsed or refractory Hodgkin's lymphoma. Ann Hematol. 2014;93(11):1745-1753. doi:10.1007/s00277-0142114-0

55. Martínez C, Díaz-López A, Rodriguez-Calvillo M, et al. Phase II trial of ofatumumab plus ESHAP (O-ESHAP) as salvage treatment for patients with relapsed or refractory classical Hodgkin lymphoma after first-line chemotherapy. Br J Haematol. 2016;174 (6):859-867. doi:10.1111/bjh.14133

56. Moskowitz AJ, Hamlin PA Jr, Perales MA, et al. Phase II study of bendamustine in relapsed and refractory Hodgkin lymphoma. J Clin Oncol. 2013;31(4):456-460. doi:10.1200/JCO.2012.45. 3308

57. O'Connor OA, Lue JK, Sawas A, et al. Brentuximab vedotin plus bendamustine in relapsed or refractory Hodgkin's lymphoma: an international, multicentre, single-arm, phase 1-2 trial. Lancet Oncol. 2018;19(2):257-266. doi:10.1016/S1470-2045(17)30912-9
58. Herrera AF, Moskowitz AJ, Bartlett NL, et al. Interim results of brentuximab vedotin in combination with nivolumab in patients with relapsed or refractory Hodgkin lymphoma. Blood. 2018;131 (11):1183-1194. doi:10.1182/blood-2017-10-811224

59. Moskowitz AJ, Advani R, Bartlett NL, et al. Brentuximab vedotin and nivolumab for relapsed or refractory classic Hodgkin lymphoma: long-term follow-up results from the single-arm phase I/II study. Blood. 2019;134(Suppl. 1):238. doi:10.1182/blood-2019122576

60. Gardai SJ, Epp A, Law C-L. Brentuximab vedotin-mediated immunogenic cell death. Cancer Res. 2015;75(15Suppl):2469. doi:10.1158/0008-5472.CAN-14-3569

61. Cao A, Heiser R, Law C-L, Gardai SJ. Auristatin-based antibody drug conjugates activate multiple ER stress response pathways resulting in immunogenic cell death and amplified T-cell responses. Cancer Res. 2016;76(14Suppl):4914. doi:10.1158/ 0008-5472.CAN-16-0584

62. Nagai H. Recent advances in Hodgkin lymphoma: interim PET and molecular-targeted therapy. Jpn J Clin Oncol. 2015;45 (2):137-145. doi:10.1093/jjco/hyu204

63. Gallamini A, Hutchings M, Rigacci L, et al. Early interim 2-[18F] fluoro-2-deoxy-D-glucose positron emission tomography is prognostically superior to international prognostic score in advancedstage Hodgkin's lymphoma: a report from a joint Italian-Danish study. J Clin Oncol. 2007;25(24):3746-3752. doi:10.1200/ JCO.2007.11.6525

64. Press OW, Li H, Schöder $\mathrm{H}$, et al. US intergroup trial of response-adapted therapy for stage III to IV Hodgkin lymphoma using early interim fluorodeoxyglucose-positron emission tomography imaging: southwest Oncology Group S0816. J Clin Oncol. 2016;34(17):2020-2027. doi:10.1200/JCO.2015.63.1119

65. Stephens DM, Li H, Schöder H, et al. Five-year follow-up of SWOG S0816: limitations and values of a PET-adapted approach for stage III/IV Hodgkin lymphoma. Blood. 2019;134 (15):1238-1246. doi:10.1182/blood.2019000719

66. Gallamini A, Tarella C, Viviani S, et al. Early chemotherapy intensification with escalated BEACOPP in patients with advanced-stage Hodgkin lymphoma with a positive interim positron emission tomography/computed tomography scan after two ABVD cycles: long-term results of the GITIL/FIL HD 0607 trial. $J$ Clin Oncol. 2018;36(5):454-462. doi:10.1200/JCO.2017.75. 2543

67. Johnson P, Federico M, Kirkwood A, et al. Adapted treatment guided by interim PET-CT scan in advanced Hodgkin's lymphoma. $N$ Engl J Med. 2016;374:2419-2429. doi:10.1056/ NEJMoa1510093

68. Zinzani PL, Broccoli A, Gioia DM, et al. Interim positron emission tomography response-adapted therapy in advanced-stage Hodgkin lymphoma: final results of the phase II part of the HD0801 study. J Clin Oncol. 2016;34(12):1376-1385. doi:10.120 0/JCO.2015.63.0699

69. Anderson RA, Remedios R, Kirkwood AA, et al. Determinants of ovarian function after response-adapted therapy in patients with advanced Hodgkin's lymphoma (RATHL): a secondary analysis of a randomised phase 3 trial. Lancet Oncol. 2018;19 (10):1328-1337. doi:10.1016/S1470-2045(18)30500-X

70. Younes A, Connors JM, Park SI, et al. Brentuximab vedotin combined with ABVD or AVD for patients with newly diagnosed Hodgkin's lymphoma: a phase 1, open-label, dose-escalation study. Lancet Oncol. 2013;14(13):1348-1356. doi:10.1016/ S1470-2045(13)70501-1

71. Connors JM, Ansell SM, Fanale M, Park SI, Younes A. Five-year follow-up of brentuximab vedotin combined with ABVD or AVD for advanced-stage classical Hodgkin lymphoma. Blood. 2017;130(11):1375-1377. doi:10.1182/blood-2017-05-784678 
72. Connors JM, Jurczak W, Straus DJ, et al. Brentuximab vedotin with chemotherapy for stage III or IV Hodgkin's lymphoma. $N$ Engl J Med. 2018;378(4):331-344. doi:10.1056/NEJMoa1 708984

73. Engert A, Diehl V, Franklin J, et al. Escalated-dose BEACOPP in the treatment of patients with advanced-stage Hodgkin's lymphoma: 10 years of follow-up of the GHSG HD9 study. $J$ Clin Oncol. 2009;27(27):4548-4554. doi:10.1200/JCO.2008.19.8820

74. Engert A, Haverkamp H, Kobe C, et al. Reduced-intensity chemotherapy and PET-guided radiotherapy in patients with advanced stage Hodgkin's lymphoma (HD15 trial): a randomised, open-label, phase 3 non-inferiority trial. Lancet. 2012;379(9828):1791-1799. doi:10.1016/S0140-6736(11)619405

75. Skoetz N, Trelle S, Rancea M, et al. Effect of initial treatment strategy on survival of patients with advanced-stage Hodgkin's lymphoma: a systematic review and network meta-analysis. Lancet Oncol. 2013;14(10):943-952. doi:10.1016/S14702045(13)70341-3

76. Engert A, Goergen H, Markova J, et al. Reduced-intensity chemotherapy in patients with advanced-stage Hodgkin lymphoma: updated results of the open-label, international, randomised phase 3 HD15 trial by the German Hodgkin study group. HemaSphere. 2017;1(1):e5. doi:10.1097/HS9.0000000000000005

77. Viviani S, Zinzani PL, Rambaldi A, et al. ABVD versus BEACOPP for Hodgkin's lymphoma when high-dose salvage is planned. N Engl J Med. 2011;365(3):203-212. doi:10.1056/ NEJMoa 1100340

78. Eichenauer DA, Plütschow A, Kreissl S, et al. Incorporation of brentuximab vedotin into first-line treatment of advanced classical Hodgkin's lymphoma: final analysis of a phase 2 randomised trial by the German Hodgkin Study Group. Lancet Oncol. 2017;18 (12):1680-1687. doi:10.1016/S1470-2045(17)30696-4

79. Stark GL, Wood KM, Jack F, et al. Hodgkin's disease in the elderly: a population-based study. Br J Haematol. 2002;119 (2):432-440. doi:10.1046/j.1365-2141.2002.03815.x

80. Levis A, Depaoli L, Bertini M, et al. Results of a low aggressivity chemotherapy regimen (CVP/CEB) in elderly Hodgkin's disease patients. Haematologica. 1996;81(5):450-456.

81. Roy P, Vaughan Hudson G, Vaughan Hudson B, Esteve J, Swerdlow AJ. Long-term survival in Hodgkin's disease patients. A comparison of relative survival in patients in trials and those recorded in population-based cancer registries. Eur $J$ Cancer. 2000;36(3):384-389. doi:10.1016/S0959-8049(99)00267-1

82. Weekes CD, Vose JM, Lynch JC, et al. Hodgkin's disease in the elderly: improved treatment outcome with a doxorubicincontaining regimen. $J$ Clin Oncol. 2002;20(4):1087-1093. doi:10.1200/JCO.2002.20.4.1087

83. Landgren O, Algernon C, Axdorph U, et al. Hodgkin's lymphoma in the elderly with special reference to type and intensity of chemotherapy in relation to prognosis. Haematologica. 2003;88 (4):438-444.

84. Evens AM, Hong F, Gordon LI, et al. The efficacy and tolerability of adriamycin, bleomycin, vinblastine, dacarbazine and Stanford $\mathrm{V}$ in older Hodgkin lymphoma patients: a comprehensive analysis from the North American intergroup trial E2496. Br J Haematol. 2013;161(1):76-86. doi:10.1111/bjh.12222

85. Forero-Torres A, Holkova B, Goldschmidt J, et al. Phase 2 study of frontline brentuximab vedotin monotherapy in Hodgkin lymphoma patients aged 60 years and older. Blood. 2015;126 (26):2798-2804. doi:10.1182/blood-2015-06-644336

86. Friedberg JW, Forero-Torres A, Bordoni RE, et al. Frontline brentuximab vedotin in combination with dacarbazine or bendamustine in patients aged $\geq 60$ years with HL. Blood. 2017;130 (26):2829-2837. doi:10.1182/blood-2017-06-787200
87. Evens AM, Connors JM, Younes A, et al. Older patients with previously untreated classical Hodgkin lymphoma: a detailed analysis from the phase 3 ECHELON-1 study. Blood. 2018;132 (Supplement1):1618. doi:10.1182/blood-2018-99-112178

88. Evens AM, Advani RH, Helenowski IB, et al. Multicenter phase II study of sequential brentuximab vedotin and doxorubicin, vinblastine, and dacarbazine chemotherapy for older patients with untreated classical Hodgkin lymphoma. J Clin Oncol. 2018;36 (30):3015-3022. doi:10.1200/JCO.2018.79.0139

89. Yasenchak CA, Bordoni R, Yazbeck V, et al. Phase 2 study of frontline brentuximab vedotin plus nivolumab in patients with Hodgkin lymphoma aged $\geq 60$ years. Blood. 2019;134 (Supplement1):237. doi:10.1182/blood-2019-124866

90. Raemaekers JM, André MP, Federico M, et al. Omitting radiotherapy in early positron emission tomography-negative stage I/II Hodgkin lymphoma is associated with an increased risk of early relapse: clinical results of the preplanned interim analysis of the randomized EORTC/LYSA/FIL H10 trial. J Clin Oncol. 2014;32 (12):1188-1194. doi:10.1200/JCO.2013.51.9298

91. MPE A, Girinsky T, Federico M, et al. Early positron emission tomography response-adapted treatment in stage I and II Hodgkin lymphoma: final results of the randomized EORTC/LYSA/FIL H10 trial. J Clin Oncol. 2017;35(16):1786-1794. doi:10.1200/ JCO.2016.68.6394

92. Engert A, Plütschow A, Eich HT, et al. Reduced treatment intensity in patients with early-stage Hodgkin's lymphoma. $N$ Engl J Med. 2010;363(7):640-652. doi:10.1056/NEJMoa1000067

93. Sasse S, Bröckelmann PJ, Goergen H, et al. Long-term follow-up of contemporary treatment in early-stage Hodgkin lymphoma: updated analyses of the German Hodgkin Study Group HD7, HD8, HD10, and HD11 trials. J Clin Oncol. 2017;35 (18):1999-2007. doi:10.1200/JCO.2016.70.9410

94. Fuchs $\mathrm{M}$, Goergen $\mathrm{H}$, Kobe $\mathrm{C}$, et al. Positron emission tomography-guided treatment in early-stage favorable Hodgkin lymphoma: final results of the international, randomized phase III HD16 trial by the German Hodgkin Study Group. $J$ Clin Oncol. 2019;37(31):2835-2845. doi:10.1200/JCO.19.00964

95. Radford J, Illidge T, Counsell N, et al. Results of a trial of PET-directed therapy for early-stage Hodgkin's lymphoma. $N \quad$ Engl $J \quad$ Med. 2015;372:1598-1607. doi:10.1056/ NEJMoa1408648

96. Abramson JS, Arnason JE, LaCasce AS, et al. Brentuximab vedotin, doxorubicin, vinblastine, and dacarbazine for nonbulky limited-stage classical Hodgkin lymphoma. Blood. 2019;134 (7):606-613. doi:10.1182/blood.2019001272

97. Chen R, Hou J, Newman E, et al. CD30 downregulation, MMAE resistance, and MDR1 upregulation are all associated with resistance to brentuximab vedotin. Mol Cancer Ther. 2015;14 (6):1376-1384. doi:10.1158/1535-7163.MCT-15-0036

98. Al-Rohil RN, Torres-Cabala CA, Patel A, et al. Loss of CD30 expression after treatment with brentuximab vedotin in a patient with anaplastic large cell lymphoma: a novel finding. J Cutan Pathol. 2016;43(12):1161-1166. doi:10.1111/cup.12797

99. Makita S, Maeshima AM, Taniguchi H, et al. Classical Hodgkin lymphoma primary refractory to brentuximab vedotin, with transformation to CD30-positive diffuse large B-cell lymphoma. Int J Hematol. 2016;104(3):396-399. doi:10.1007/s12185-0162018-y

100. Diefenbach CS, Hong F, Ambinder R, et al. Extended follow-up of a phase I trial of ipilimumab, nivolumab and brentuximab vedotin in relapsed Hodgkin lymphoma: a trial of the ECOG-ACRIN research group (E4412). Hematol Oncol. 2019;37(Supp12):123-124. doi:10.1002/hon.83_2629

101. Küppers R. The biology of Hodgkin's lymphoma. Nat Rev Cancer. 2009;9(1):15-27. doi:10.1038/nrc2542 
102. Mathas S, Hartmann S, Küppers R. Hodgkin lymphoma: pathology and biology. Semin Hematol. 2016;53(3):139-147. doi:10.1053/j.seminhematol.2016.05.007

103. Blum KA, Johnson JL, Niedzwiecki D, Canellos GP, Cheson BD, Bartlett NL. Single agent bortezomib in the treatment of relapsed and refractory Hodgkin lymphoma: cancer and leukemia Group B protocol 50206. Leuk Lymphoma. 2007;48(7):1313-1319. doi:10.1080/10428190701411458

104. Younes A, Romaguera J, Fanale M, et al. Phase I study of a novel oral Janus kinase 2 inhibitor, SB1518, in patients with relapsed lymphoma: evidence of clinical and biologic activity in multiple lymphoma subtypes. J Clin Oncol. 2012;30(33):4161-4167. doi:10.1200/JCO.2012.42.5223

105. Van Den Neste E, André M, Gastinne T, et al. A phase II study of the oral JAK1/JAK2 inhibitor ruxolitinib in advanced relapsed/ refractory Hodgkin lymphoma. Haematologica. 2018;103 (5):840-848. doi:10.3324/haematol.2017.180554

106. Johnston PB, Inwards DJ, Colgan JP, et al. A Phase II trial of the oral mTOR inhibitor everolimus in relapsed Hodgkin lymphoma. Am J Hematol. 2010;85(5):320-324. doi:10.1002/ajh.21664

107. Gopal AK, Fanale MA, Moskowitz CH, et al. Phase II study of idelalisib, a selective inhibitor of PI $3 \mathrm{~K} \delta$, for relapsed/refractory classical Hodgkin lymphoma. Ann Oncol. 2017;28(5):1057-1063. doi:10.1093/annonc/mdx028

108. Oki Y, Fanale M, Romaguera J, et al. Phase II study of an AKT inhibitor MK2206 in patients with relapsed or refractory lymphoma. Br J Haematol. 2015;171(4):463-470. doi:10.1111/bjh.13603
109. Younes A, Sureda A, Ben-Yehuda D, et al. Panobinostat in patients with relapsed/refractory Hodgkin's lymphoma after autologous stem-cell transplantation: results of a phase II study. J Clin Oncol. 2012;30(18):2197-2203. doi:10.1200/JCO.2011.38.1350

110. Younes A, Oki Y, Bociek RG, et al. Mocetinostat for relapsed classical Hodgkin's lymphoma: an open-label, single-arm, phase 2 trial. Lancet Oncol. 2011;12(13):1222-1228. doi:10.1016/ S1470-2045(11)70265-0

111. Batlevi CL, Kasamon Y, Bociek RG, et al. ENGAGE- 501: phase II study of entinostat (SNDX-275) in relapsed and refractory Hodgkin lymphoma. Haematologica. 2016;101(8):968-975. doi:10.3324/haematol.2016.142406

112. Walewski J, Paszkiewicz-Kozik E, Borsaru G, et al. Resminostat in patients with relapsed or refractory Hodgkin lymphoma: results of the phase II SAPHIRE study. Leuk Lymphoma. 2019;60 (3):675-684. doi:10.1080/10428194.2018.1492122

113. Bartlett NL, Chen R, Fanale MA, et al. Retreatment with brentuximab vedotin in patients with CD30-positive hematologic malignancies. J Hematol Oncol. 2014;7:24. doi:10.1186/17568722-7-24

114. Fukuhara N, Yamamoto G, Tsujimura H, et al. Retreatment with brentuximab vedotin in patients with relapsed/refractory classical Hodgkin lymphoma or systemic anaplastic large-cell lymphoma: a multicenter retrospective study. Leuk Lymphoma. 2019:1-5. doi:10.1080/10428194.2019.1654100.

\section{Publish your work in this journal}

OncoTargets and Therapy is an international, peer-reviewed, open access journal focusing on the pathological basis of all cancers, potential targets for therapy and treatment protocols employed to improve the management of cancer patients. The journal also focuses on the impact of management programs and new therapeutic agents and protocols on patient perspectives such as quality of life, adherence and satisfaction. The manuscript management system is completely online and includes a very quick and fair peer-review system, which is all easy to use. Visit http://www.dovepress.com/ testimonials.php to read real quotes from published authors. 